\title{
Tunable Carbon Surface from Mono- to Multi-Metallic Single Atoms
}

Weihong Lai, Heng Wang, Quan jiang, Zichao Yan, Hanwen Liu, Yaojie Lei, Lingfei Zhao, Wang Zhang, Lei Wang, Hirofumi Yoshikawa, Daiju Matsumura, Yunxiao Wang, Qiao sun, Jiazhao Wang, Huakun Liu, Shulei Chou, Shixue Dou

Submitted date: 07/05/2020 - Posted date: 08/05/2020

Licence: CC BY-NC-ND 4.0

Citation information: Lai, Weihong; Wang, Heng; jiang, Quan; Yan, Zichao; Liu, Hanwen; Lei, Yaojie; et al. (2020): Tunable Carbon Surface from Mono- to Multi-Metallic Single Atoms. ChemRxiv. Preprint. https://doi.org/10.26434/chemrxiv.12264083.v1

Herein, we develop a non-selective charge compensation strategy to prepare multi-single-atom doped carbon (MSAC) in which a sodium p-toluenesulfonate (PTS-Na) doped polypyrrole (S-PPy) polymer is designed to anchor discretionary mixtures of multiple metal cations, including iron $\left(\mathrm{Fe}^{3+}\right)$, cobalt $\left(\mathrm{Co}^{3+}\right)$, ruthenium $\left(\mathrm{Ru}^{3+}\right)$, palladium $\left(\mathrm{Pd}^{2+}\right)$, indium $\left(\mathrm{In}^{3+}\right)$, iridium $\left(\mathrm{Ir}^{2+}\right)$, and platinum $\left(\mathrm{Pt}^{2+}\right)$. As illustrated in Figure 1, the carbon surface can be tuned with different level of compositional complexities, including unary Pt $@$ @NC, binary (MSAC-2, (PtFe) $@ @ N C)$, ternary (MSAC-3, (PtFelr), @NC), quaternary (MSAC-4, (PtFelrRu) $@ @ N C)$, quinary (MSAC-5, (PtFelrRuCo) 1 @NC), senary (MSAC-6, (PtFelrRuCoPd), @NC), and septenary (MSAC-7, (PtFelrRuCoPdln)_@NC) samples. The structural evolution of carbon surface dictates the activities of both ORR and HER. The senary MSAC-6 achieves the ORR mass activity of $18.1 \mathrm{~A} \cdot \mathrm{mg}_{\text {metal }}{ }^{-1}$ at $0.9 \mathrm{~V}$ (Vs reversible hydrogen electrode (RHE)) over $30 \mathrm{~K}$ cycles, which is 164 times higher than that of commercial $\mathrm{Pt} / \mathrm{C}$. The quaternary MSAC-4 presented a comparable HER catalytic capability with that of Pt/C. These results indicate that the highly complexed carbon surface can enhance its ability over general electrochemical catalytic reactions. The mechanisms regarding of the ORR and HER activities of the alternated carbon surface are also theoretically and experimentally investigated in this work, showing that the synergistic effects amongst the co-doped atoms can activate or inactivate certain single-atom sites.

File list (2)

manuscript-non-linked.pdf (4.50 MiB)

view on ChemRxiv - download file 


\section{Tunable carbon surface from mono- to multi-metallic single atoms}

Wei-Hong Lai, ${ }^{1,2,3}$ Heng Wang, ${ }^{4}$ Quan Jiang, ${ }^{5,8}$ Zi-Chao Yan, ${ }^{3}$ Han-Wen Liu, ${ }^{3}$ Yao-Jie Lei, ${ }^{3}$ Lingfei Zhao, ${ }^{3}$ Wang zhang, ${ }^{1}$ Lei Wang, ${ }^{1 *}$ Hirofumi Yoshikawa, ${ }^{5}$ Daiju Matsumura ${ }^{6}$ Yun-Xiao Wang, ${ }^{3 *}$ Qiao Sun, ${ }^{7}$ Jia-Zhao Wang, ${ }^{3}$ Hua-Kun Liu, ${ }^{3}$ Shu-Lei Chou, ${ }^{3 *}$ Shi-Xue Dou ${ }^{3}$

${ }^{1}$ College of Materials Science and Engineering, Shenzhen University, Shenzhen 518060, China.

${ }^{2}$ College of Physics and Optoelectronic Engineering, Shenzhen University, Shenzhen 518060, China.

${ }^{3}$ Institute for Superconducting \& Electronic Materials, University of Wollongong, Innovation Campus, Wollongong, NSW 2500, Australia.

${ }^{4}$ School of Material and Chemical Engineering, Zhengzhou University of Light Industry, Zhengzhou 450002, China.

${ }^{5}$ State Key Laboratory of Radiation Medicine and Protection, Collaborative Innovation Centre of Radiation Medicine of Jiangsu Higher Education Institutions, School for Radiological and Interdisciplinary Sciences, Soochow University, Suzhou 215123, China.

${ }^{6}$ School of Science and Technology, Kwansei Gakuin University, 2-1 Gakuen, Sanda, Hyogo 6691337, Japan.

${ }^{7}$ Quantum Beam Science Center, Japan Atomic Energy Agency, Sayo-gun, Hyogo 679-5148, Japan.

${ }^{8}$ Key Laboratory for Ultrafine Materials of Ministry of Education, Shanghai Key Laboratory of Advanced Polymeric Materials, School of Materials Science and Engineering, East China University of Science and Technology, Shanghai 200237, China.

Abstract: The control of carbon surface requires a highly compositional complexity at atomic scale, which is vital but challenging. Herein, we develop a general strategy to co-doping up to seven species of metallic single atoms into nitrogen-doped carbon (NC), leading to multi-singleatom doped carbon (MSAC), denoted as MSAC-7 ((PtFeIrRuCoPdIn)1@NC). Significantly, we can flexibly tune the complexity of carbon surface, including senary (MSAC-6, (PtFeIrRuCoPd)1@NC), quinary (MSAC-5, (PtFeIrRuCo)1@NC), quaternary (MSAC-4, (PtFeIrRu)1@NC), ternary (MSAC-3, (PtFeIr)1@NC), and binary (MSAC-2, (PtFe)1@NC) structures. The MSAC demonstrates an unexpected catalytic performance towards oxygen reduction reactions (ORR) and hydrogen evolution reactions (HER), that is, the mass activity of ORR of noble metals of MSAC-6 shows 164 times higher than Pt/C and MSAC-4 has a comparable HER performance with $\mathrm{Pt} / \mathrm{C}$. Significantly, the electrocatalytic behaviors of MSAC have been theorectically and experimentally revealed. This work confirms that MSAC can be an efficient catalysts by tuning the complexity of carbon surface due to the synergistic effects amongst single atoms. The developed non-selective charge compensation method as a versatile tool builds a library of multi-metallic single-atom catalysts (SACs), giving a new insight into primary surface science and extending the realm of SACs. 
Heterogeneous surfaces are of intrinsic importance for catalysis, which provides active sites and the natural environment to accelerate a wide range of reactions. ${ }^{1}$ Heteroatom-doped carbon materials represent as a unique class of effective catalysts, which can induce disorder and defects and change the electronic structure of the carbon matrix due to the difference of atomic radius, bond length and electronegativity. ${ }^{2}$ For instance, nitrogen-doping can lead to positive charge on carbon, and the neighbouring carbon can serve as active sites. $\mathrm{N}$ dopant is essential for carbon matrix due to its electron accepting ability and superior electrochemical stability. ${ }^{3}$ Boron and phosphorus possess lower electronegativity than that of carbon, thus the doped B or P dopants would become inferior active sites. ${ }^{4}$ Metallic single-atom doping, on the other hand, thrives on maximal atomic utilization as well as distinct electronic and geometric structures. ${ }^{1,}$ 5-6 Correspondingly, various single-atom catalysts have been fabricated and proven to deliver unexpected catalytic performance in a wide scope of reactions, such as hydrogenation reactions, ${ }^{7-}$ ${ }^{9}$ hydrogen evolution reactions, ${ }^{10-11}$ oxygen reduction reactions, ${ }^{12}{ }^{13}$ oxygen evolution reactions (OER), ${ }^{13} \mathrm{CO}$ oxidation reactions, ${ }^{8,}{ }^{14} \mathrm{CO}_{2}$ reduction reactions, ${ }^{15} \mathrm{NO}$ oxidation reactions, ${ }^{11} \mathrm{~N}_{2}$ reduction reactions (NRR), ${ }^{16}$ electrochemical reactions in batteries, ${ }^{17-19}$ and other reactions. ${ }^{20-23}$ Mono single-atom metals can be anchored on carbon backbones via defect engineering, ${ }^{24}$ atomic layer deposition, ${ }^{25}$ and coordinating with organic ligands. ${ }^{12}$

Notably, Beller et al. have illuminated the direction on bi- and multimetallic SACs for the next years, but it is extremely challenging to co-disperse different metallic elements in isolation on a support. Two reports are initiated to explore the feasibility of bi-metallic SACs, including $\mathrm{Pt}_{1}-\mathrm{Sn}_{1}$, as well as $\mathrm{Fe} / \mathrm{Co}, \mathrm{Ru} / \mathrm{Fe}, \mathrm{Ru} / \mathrm{Co}$, and $\mathrm{Ru} / \mathrm{Ni}$, respectively. ${ }^{26}{ }^{27}$ Also, a defected $\mathrm{C} / \mathrm{N}$ graphene surface modified with atomic Pt-Co suggested high ORR activity via synergistic interactions between atomic Pt-Co pair and the neighboring non-metal atoms. ${ }^{28}$ It is noticeable that the atomic interaction amongst the adjacent atoms in a certain local environment can significantly tailor the electronic structure of the metal atoms and alter charge distribution to form atomic Co-Pt-N-C coordination structures as active sites, thereby enhancing ORR performance. Thus, increasing atomic metal species on carbon support is vital to tune the structural disorder of carbon surface, which, in turn, affects the electronic structures and physical properties of carbon skeletons, leading to a new generation of high-activity SACs for a large variety of applications, especially for domino and tandem reactions in the future. The successful preparation of high compositional single-atom doped carbon is also highly significant to the synthetic chemistry and life-science as well as to explore the limitation of metal-doped carbon materials.

Herein, we develop a non-selective charge compensation strategy to prepare multi-single-atom doped carbon (MSAC) in which a sodium p-toluenesulfonate (PTS-Na) doped polypyrrole (S-PPy) polymer is designed to anchor discretionary mixtures of multiple metal cations, including iron $\left(\mathrm{Fe}^{3+}\right)$, cobalt $\left(\mathrm{Co}^{3+}\right)$, ruthenium $\left(\mathrm{Ru}^{3+}\right)$, palladium $\left(\mathrm{Pd}^{2+}\right)$, indium $\left(\mathrm{In}^{3+}\right)$, iridium $\left(\mathrm{Ir}^{2+}\right)$, and platinum $\left(\mathrm{Pt}^{2+}\right)$. As illustrated in Figure 1, the carbon surface can be tuned with different level of compositional complexities, including unary $\mathrm{Pt}_{1} @ \mathrm{NC}$, binary (MSAC-2, $\left.(\mathrm{PtFe})_{1} @ \mathrm{NC}\right)$, ternary (MSAC-3, (PtFeIr)1@NC), quaternary (MSAC-4, (PtFeIrRu)1@NC), quinary (MSAC-5, (PtFeIrRuCo)1@NC), senary (MSAC-6, (PtFeIrRuCoPd)1@NC), and septenary (MSAC-7, (PtFeIrRuCoPdIn)1@NC) samples. The structural evolution of carbon surface dictates the activities of both ORR and HER. The senary MSAC-6 achieves the ORR mass activity of 18.1 $\mathrm{A} \cdot \mathrm{mg}_{\mathrm{metal}^{-1}}{ }^{-1}$ at $0.9 \mathrm{~V}$ (Vs reversible hydrogen electrode (RHE)) over $30 \mathrm{~K}$ cycles, which is 164 times higher than that of commercial $\mathrm{Pt} / \mathrm{C}$. The quaternary MSAC-4 presented a comparable HER catalytic capability with that of $\mathrm{Pt} / \mathrm{C}$. These results indicate that the highly complexed carbon surface can enhance its ability over general electrochemical catalytic reactions. The mechanisms 
regarding of the ORR and HER activities of the alternated carbon surface are also theoretically and experimentally investigated in this work, showing that the synergistic effects amongst the codoped atoms can activate or inactivate certain single-atom sites.

\section{Results}

\section{Structural characterization}

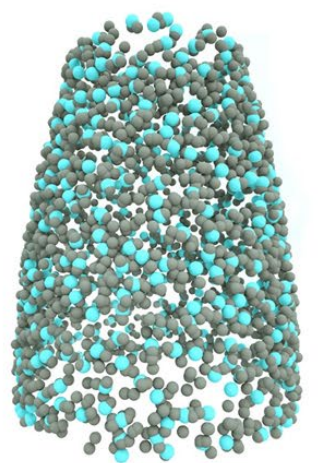

NC

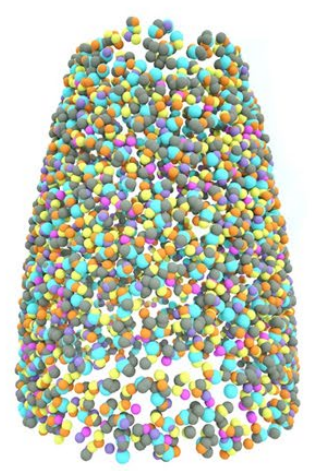

MSAC-4

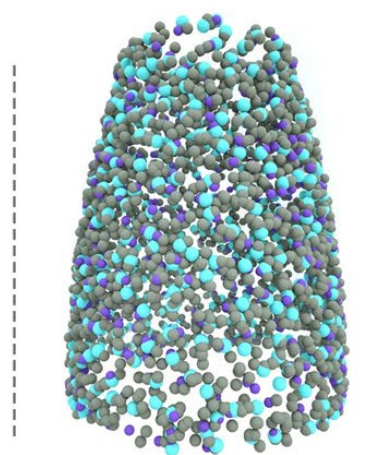

$\mathrm{Pt}_{1} @ \mathrm{NC}$

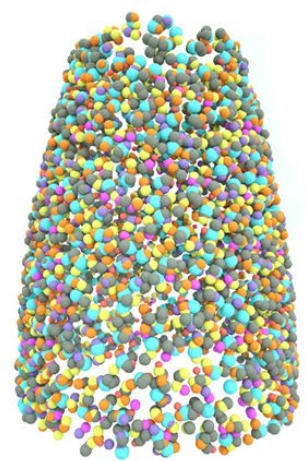

MSAC-5

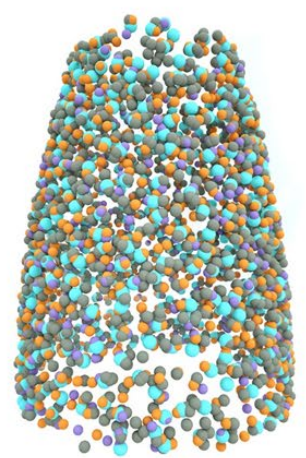

MSAC-2

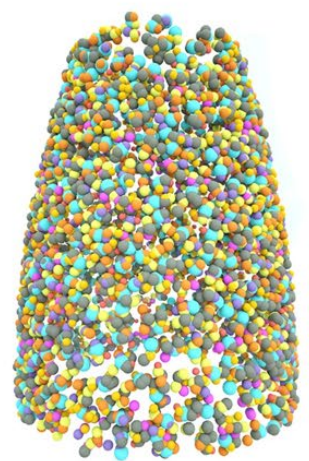

MSAC-6

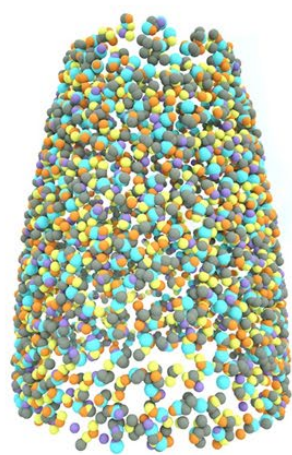

MSAC-3

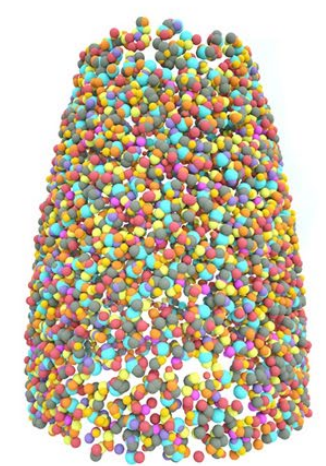

MSAC-7

Figure 1. The illustration of structure of MSAC

It is known that the different metal cations can easily aggregate together to form particles due to the different redox potential especially under a high-temperature sintering. Stabilizing metal cations with strong bonding, thus, is vital for the synthesis of multi-single-atom doped carbon. In this work, PTS-Na is utilized as the functionalized counterion, interacting with metal cations (Figure S1). The sodium ions on PTS-Na migrate off the oxidized S-PPy during the polymerization process and are compensated via metal ions $\left(\mathrm{S}-\mathrm{PPy}-\mathrm{M}^{\mathrm{x}}\right)$, resulting in a stabilized bond during the sintering process. After high-temperature sintering, the precursors of S-PPy stabilized metal cations can be converted into single atom metals implanted onto nitrogen doped carbon fibres with tailored surface. In particular, the precursors of metal cations can be controlled to contain various compositional species from elements of $\mathrm{Pt}, \mathrm{Fe}, \mathrm{Ir}, \mathrm{Ru}, \mathrm{Co}, \mathrm{Pd}$, and $\mathrm{In}$. As shown in Figure 1, different combinations of cations, including $\mathrm{Pt}^{2+}, \mathrm{Pt}^{2+} / \mathrm{Fe}^{3+}, \mathrm{Pt}^{2+} / \mathrm{Fe}^{3+} / \mathrm{Ir}^{2+}, \mathrm{Pt}^{2+} / \mathrm{Fe}^{3+} / \mathrm{Ir}^{2+} / \mathrm{Ru}^{3+}$, $\mathrm{Pt}^{2+} / \mathrm{Fe}^{3+} / \mathrm{Ir}^{2+} / \mathrm{Ru}^{3+} / \mathrm{Co}^{3+}, \mathrm{Pt}^{2+} / \mathrm{Fe}^{3+} / \mathrm{Ir}^{2+} / \mathrm{Ru}^{3+} / \mathrm{Co}^{3+} / \mathrm{Pd}^{2+}$, and $\mathrm{Pt}^{2+} / \mathrm{Fe}^{3+} / \mathrm{Ir}^{2+} / \mathrm{Ru}^{3+} / \mathrm{Co}^{3+} / \mathrm{Pd}^{2+} / \mathrm{In}^{3+}$, are selected to prepare the controllable surface, leading to the formation of $\mathrm{Pt}_{1} @ \mathrm{NC}$, binary (MSAC2, (PtFe)1@NC), ternary (MSAC-3, (PtFeIr)1@NC), quaternary (MSAC-4, (PtFeIrRu)1@NC), quinary (MSAC-5, (PtFeIrRuCo)1@NC), senary (MSAC-6, (PtFeIrRuCoPd)1@NC), and septenary (MSAC-7, (PtFeIrRuCoPdIn)1@NC) samples, respectively. In contrast, Pt particles are 
formed on carbon framework when PTS-Na is not added on PPy surface as functional groups (Figure S2), indicating that the PTS-Na plays a vital role in maintaining the single-atom status of various metals.

As shown in Figure 2AI, the high angle annular dark field (HAADF)-scanning transmission electron microscopy (STEM) image at high resolution verifies that a variety of the bright-contrast single atoms are uniformly dispersed on carbon matrix surface of MSAC-7 without agglomeration during the high-temperature annealing. The STEM-energy dispersive spectroscopy (EDS) elemental maps further confirm that the involved elements $(\mathrm{M}=\mathrm{Pt}, \mathrm{Ir}, \mathrm{Pd}, \mathrm{Ru}, \mathrm{In}, \mathrm{Co}, \mathrm{Fe})$ are uniformly distributed over the entire architecture (Figure 2AII-VIII, Figure S3). The overlapped elemental signals on the corresponded architecture demonstrate a two-dimensional colourful scattergram (Figure 2AIX), indicating a compositional high-complexity carbon surface.
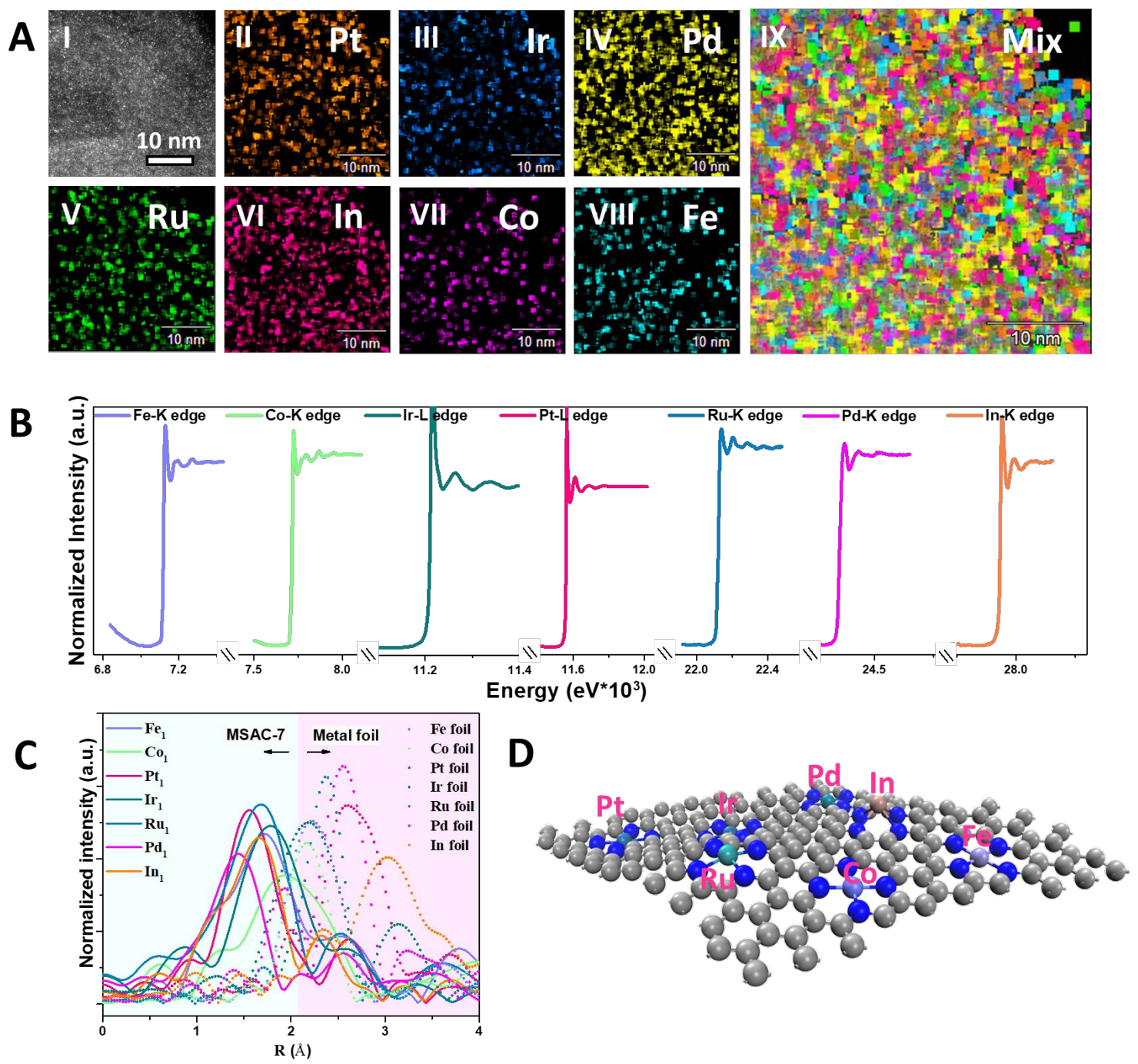

Figure 2. The surface structure of MSAC-7. (A) The HAADF image (I) and the corresponding elemental maps of Pt, Ir, Pd, Ru, In, Co, Fe of MSAC-7 (II-IX). (B) The XAS spectra across different energy regions of dissimilar elements in MSAC-7. (C) The FT- EXAFS spectra of the composed elements on MSAC-7 and their corresponding foils. (D) The illustration of the fitted structure of MSAC-7. The black ball represents carbon, the blue ball represents nitrogen. 
To explore the local order information of metal atoms of MSAC, the X-ray adsorption spectroscopy (XAS) was conducted due to its atomic selectivity and high sensitivity ${ }^{29-30}$. The both parts of X-ray absorption near edge structure (XANES) and X-ray absorption fine structure (EXAFS) of the obtained XAS have been demonstrated in Figure 2B, which shows the specific energy regions across a range of metal atoms in MSAC-7, including Fe-K edge, Co-K edge, Ir-L edge, Pt-L edge, Ru-K edge, Pd-K edge, and In-K edge. In principle, the successful detection of these metal atoms confirms the multi-metallic carbon surface, which is consistent with the EDS results. Also, the Fourier transform (FT)-EXAFS spectra of MSAC-7 and the referenced metal foil were employed to analyse their coordination environment. As shown in Figure 2C, R-space of all metal atoms of MSAC-7, including $\mathrm{Fe}_{1}, \mathrm{Co}_{1}, \mathrm{Ir}_{1}, \mathrm{Pt}_{1}, \mathrm{Ru}_{1}, \mathrm{Pd}_{1}$, and $\mathrm{In}_{1}$, shows a blue shift to a lowcoordination bonding distance, and in turn, their corresponding foils show their characteristic metal-metal distance in a high-coordination region. These results indicate that the metal atoms in MSAC-7 are isolated as single-atom dopants instead of metal phase. Additionally, the EXAFS fitting of R-space was performed for simulating their coordinated structure of each single atom of MSAC-7. Their simulated model of local structure suggests the different atoms form a similar tetradentate structures ( $\mathrm{Pt}_{1}-4 \mathrm{~N}, \mathrm{Fe}_{1}-4 \mathrm{~N}, \mathrm{Pd}_{1}-4 \mathrm{~N}$, Ir $1-4 \mathrm{~N}, \mathrm{Ru}-4 \mathrm{~N}, \mathrm{Co}-4 \mathrm{~N}$, and In $1-4 \mathrm{~N}$ ) (Figure S4, Table S1). The carbon surface of MSAC-7 is supposed to consist of these individual single-atom complex as shown in Figure 2D. The loading mass of metal elements on MSAC-7 was confirmed by inductively coupled plasma-optical emission spectrometry (ICP-AES) (Table S2).
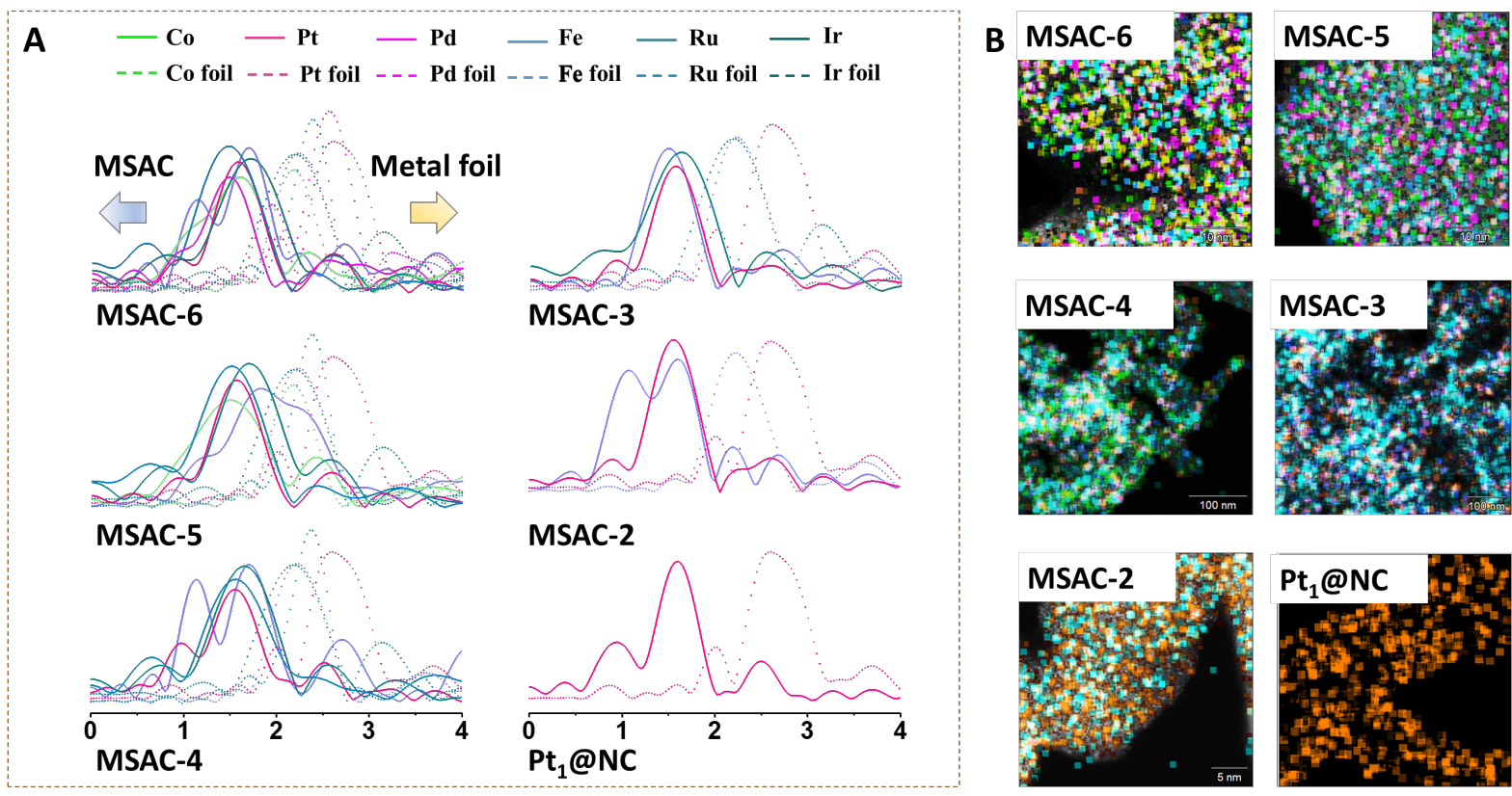

Figure 3. The tune of multi-single-atom structure of carbon surface. (A) The FT-EXAFS spectra and STEM elemental maps (inset images) of the composed elements of MSAC-6, MSAC5, MSAC-4, MSAC-3, MSAC-2, and Pt 1 NC, showing FT- EXAFS spectra of their referenced metal foils as well. (B) The mixed STEM-EDS elemental maps of MSAC-6, MSAC-5, MSAC-4, MSAC-3, MSAC-2, and Pt 1 NC.

Also, we demonstrated the versatility in preparing a series of carbon surface from high complexity to low complexity: MSAC-6, MSAC-5, MSAC-4, MSAC-3, MSAC-2, and unary $\mathrm{Pt}_{1} @ N C$. Similar to multimetallic single atoms in MSAC-7, the metal atoms in MSAC-6, MSAC5, MSAC-4, MSAC-3, MSAC-2, and Pt $1 @ \mathrm{NC}$ are anchored on carbon surface as isolated single 
atoms, showing a number of high-contrast bright spots (Figure S5). The involved elements are uniformly distributed across their respective architectures (Figure S6-12). The composed elements of MSAC-6, MSAC-5, MSAC-4, MSAC-3, MSAC-2, and Pt 1 @NC were also confirmed by XAS spectra (Figure S13). Additionally, the EXAFS spectra of MSAC-6, MSAC-5, MSAC-4, MSAC3, MSAC-2, and Pt $@$ NC (Figure 3A) show similar low coordination shell without metal-metal characteristic peaks, which confirm their isolated local structures. The success in tuning the diversity of single-atom metal dopants indicates the proposed method enable to precisely control the single-atom dopants of the carbon surface as well as the polybasic compositions. The mixed EDS elemental mappings as shown in Figure 3B visually present that a variety of elements can be evenly distributed on carbon surface without agglomeration. This result also indicates that all metal species can be tuned in a descending order from senary to unary. Furthermore, the X-ray diffraction (XRD) patterns of all MSAC samples are well consistent with the carbon. There are no metal phases formed in any MSAC samples, further implying that the loaded metals are very likely to be atomically dispersed on the support without agglomeration (Figure S14). For comparison, a series of unary single-atom catalysts, including Ir $1 @ \mathrm{NC}, \mathrm{Ru}_{1} @ \mathrm{NC}, \mathrm{Co}_{1} @ \mathrm{NC}, \mathrm{Fe}_{1} @ \mathrm{NC}, \mathrm{In}_{1} @ \mathrm{NC}$, and $\mathrm{Pd}_{1} @ \mathrm{NC}$ were also prepared (Figure S15).

\section{Electrochemical characterization}
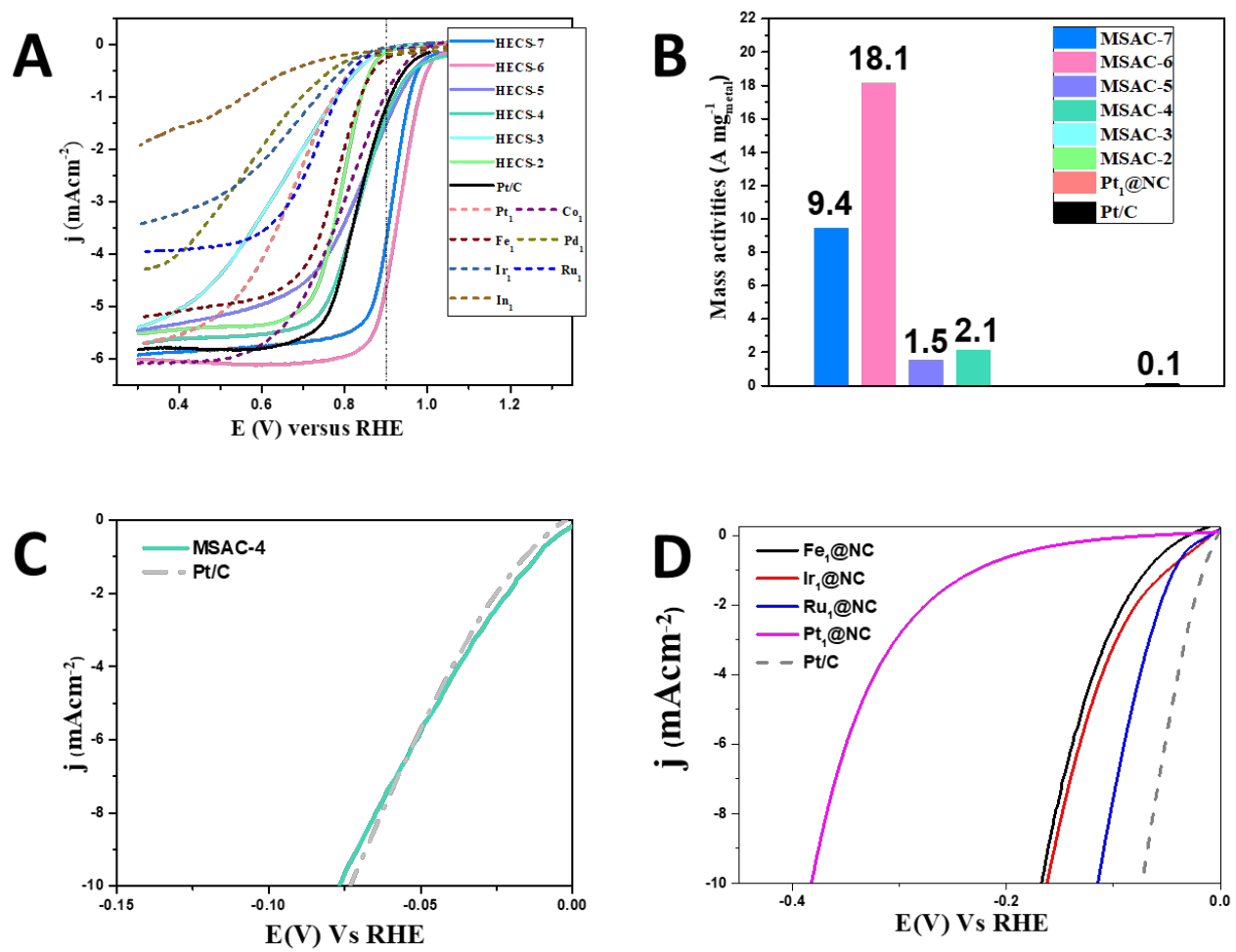

Figure 4. ORR and HER performance. (A) ORR polarization curves for MSAC-7, MSAC-6, MSAC-5, MSAC-4, MSAC-3, MSAC-2, Pt $1 @ N C, \mathrm{Ir}_{1} @ N C, \mathrm{Ru}_{1} @ \mathrm{NC}, \mathrm{Co} 1 @ \mathrm{NC}, \mathrm{Fe}_{1} @ \mathrm{NC}$, $\mathrm{Pd}_{1} @ \mathrm{NC}, \mathrm{In}_{1} @ \mathrm{NC}$, and Pt/C (B) The ORR mass activity of MSAC-7, MSAC-6, MSAC-5, MSAC-4, MSAC-3, MSAC-2, Pt @@NC, and Pt/C. (C) Polarization curves of the HER of samples: MSAC-4 and commercial Pt/C. (D) Polarization curves of the HER of samples: Pt1@NC, Ir1@NC, $\mathrm{Ru} 1 @ \mathrm{NC}, \mathrm{Fe}_{1} @ \mathrm{NC}$ and commercial Pt/C. 
Compared with the pristine carbon surface, the physical properties of MSAC are changed due to the multi-composition-induced disordered properties. As a proof of our concept, these as-prepared MSAC samples were utilized to comprehensively investigate their catalytic activities on ORR and HER, respectively. Figure 4A shows the ORR polarization curves of different catalysts recorded at room temperature at a sweep rate of $10 \mathrm{mV} \mathrm{s}^{-1}$ with a rotation rate of $1600 \mathrm{rpm}$ in $\mathrm{O}_{2}$-saturated $0.1 \mathrm{M} \mathrm{KOH}$ solution. For a clear comparison, the unary single atom materials, including $\mathrm{Pt}_{1} @ \mathrm{NC}$, $\mathrm{Fe}_{1} @ \mathrm{NC}, \mathrm{Ir}_{1} @ \mathrm{NC}, \mathrm{Ru}_{1} @ \mathrm{NC}, \mathrm{Co}_{1} @ \mathrm{NC}, \mathrm{Pd}_{1} @ \mathrm{NC}$, and In $1 @ \mathrm{NC}$, have been prepared. It is evident that the MSAC-6 has the highest half-wave potential $\left(\mathrm{E}_{1 / 2}=0.93 \mathrm{~V}\right)$, compared with the individual single-atom counterparts, including Pt $1 @ N C, \mathrm{Fe}_{1} @ \mathrm{NC}, \mathrm{Ir}_{1} @ \mathrm{NC}, \mathrm{Ru}_{1} @ \mathrm{NC}, \mathrm{Co} 1 \mathrm{NC}$, and $\mathrm{Pd}_{1} @ \mathrm{NC}$. The result indicates that the regulation of multiple elements of MSAC would synergistically improve ORR performance. Additionally, the mass activity of MSAC-6 can be calculated to be $18.1 \mathrm{~A} \cdot \mathrm{mg}_{\text {metal }^{-1}}$ at $0.9 \mathrm{~V}$ (Vs reversible hydrogen electrode (RHE)), which is 164 times higher than commercial $\mathrm{Pt} / \mathrm{C}\left(0.11 \mathrm{~A} \cdot \mathrm{mg}_{\mathrm{Pt}}{ }^{-1}\right)$ (Figure $\left.4 \mathrm{~B}\right)$. The number of electrons transferred (n) is estimated to be $\sim 3.8$ at $0.3-0.6 \mathrm{~V}$ from the slopes of the Koutecky-Levich plots, indicating the nearly complete reduction of $\mathrm{O}_{2}$ (Figure $\mathrm{S} 16$ ). To the best of our knowledge, the MSAC-6 achieved the highest ORR mass activity in alkaline solution under comparable conditions, including various PMG-based nanomaterials (Table S3). An accelerated durability test between 0.6 and $1.0 \mathrm{~V}$ shows that there is no obvious shift at $0.9 \mathrm{~V}$ after 30000 cycles (Figure S17). Notably, the mass activity at $0.9 \mathrm{~V}$ increases in the sequence: $\mathrm{Pt}_{1} @ \mathrm{NC}=\mathrm{MSAC}-2=\mathrm{MSAC}-$ $3<\mathrm{Pt} / \mathrm{C}<\mathrm{MSAC}-5<\mathrm{MSAC}-4<\mathrm{MSAC}-7<\mathrm{MSAC}-6$, indicating that the excellent ORR performance can be only achieved when the carbon matrix is controlled to high compositional single-atom dopants with exceeding four metallic elements. It is noticeable that the MSAC-7 also delivers an excellent ORR activity with a high half-wave potential $\left(\mathrm{E}_{1 / 2}=0.92 \mathrm{~V}\right)$ and a mass activity of $9.2 \mathrm{~A} \cdot \mathrm{mg}_{\text {metal }}{ }^{-1}$ at $0.9 \mathrm{~V}$, which is much better than those of $\mathrm{Pt} / \mathrm{C}$. These results indicate that carbon surface with high elemental complexity can present the enhanced ORR activity beyond that of any unary catalytic units of their corresponding elements. The alternative metal combination, however, would affect their ORR performance either. For instance, even though further doped with extra In1, the MSAC-7 ((PtFeIrRuCoPdIn)1@NC) shows inferior performance than MSAC-6 ((PtFeIrRuCoPd)1@NC). Moreover, the diverse compositions of MSAC enable a wide potential application. As shown in Figure 4C, the MSAC-4 achieved a comparable HER performance with the commercial $\mathrm{Pt} / \mathrm{C}$ in $1 \mathrm{M} \mathrm{KOH}$ solution. As shown in Figure 4D, however, the corresponding unary single-atom catalysts, including $\mathrm{Pt}_{1} @ \mathrm{NC}, \mathrm{Fe}_{1} @ \mathrm{NC}, \mathrm{Ir} 1 @ \mathrm{NC}$, and $\mathrm{Ru}_{1} @ \mathrm{NC}$, indicate an inferior HER performance compared with Pt/C. There results further indicate that the multimetalllic carbon surface can enhance the catalytic capability and show highly potential applications as new multifunctional catalysts.

\section{Discussion}

\section{Catalytic mechanism of MSAC for ORR}

Generally, the ORR involves an indirect four-electron mechanism, of which the two-electron pathway converses to hydrogen peroxide, followed by further reduction to water ${ }^{31}$. As a consequence, the four-electron ORR has multiple intermediates, involving $\mathrm{OOH}^{*}, \mathrm{O}^{*}$, and $\mathrm{OH}^{*}$, which are strongly correlated. The binding energies of $\mathrm{OOH}^{*}, \mathrm{O}^{*}$, and $\mathrm{OH}^{*}$ are expected to be moderate but not too strong or too week. For instance, the strong bond between homogeneous catalyst and oxygen limits the proton-electron transfer to $\mathrm{O}^{*}$ or $\mathrm{OH}^{*}$ and in turn, for materials that bind oxygen too weakly, the activity is limited by proton-electron transfer to $\mathrm{O}_{2} *$ or splitting of $\mathrm{O}$ $\mathrm{O}$ bond. For multi-metallic carbon surface, thus, the compositional complexity of catalysts is 
expected to gentle the adsorption energy of intermediates due to the synergistic effect amongst metals. Also, the atomic-level dispersion can probably overcome the kinetic challenges in diffusion of intermediates.
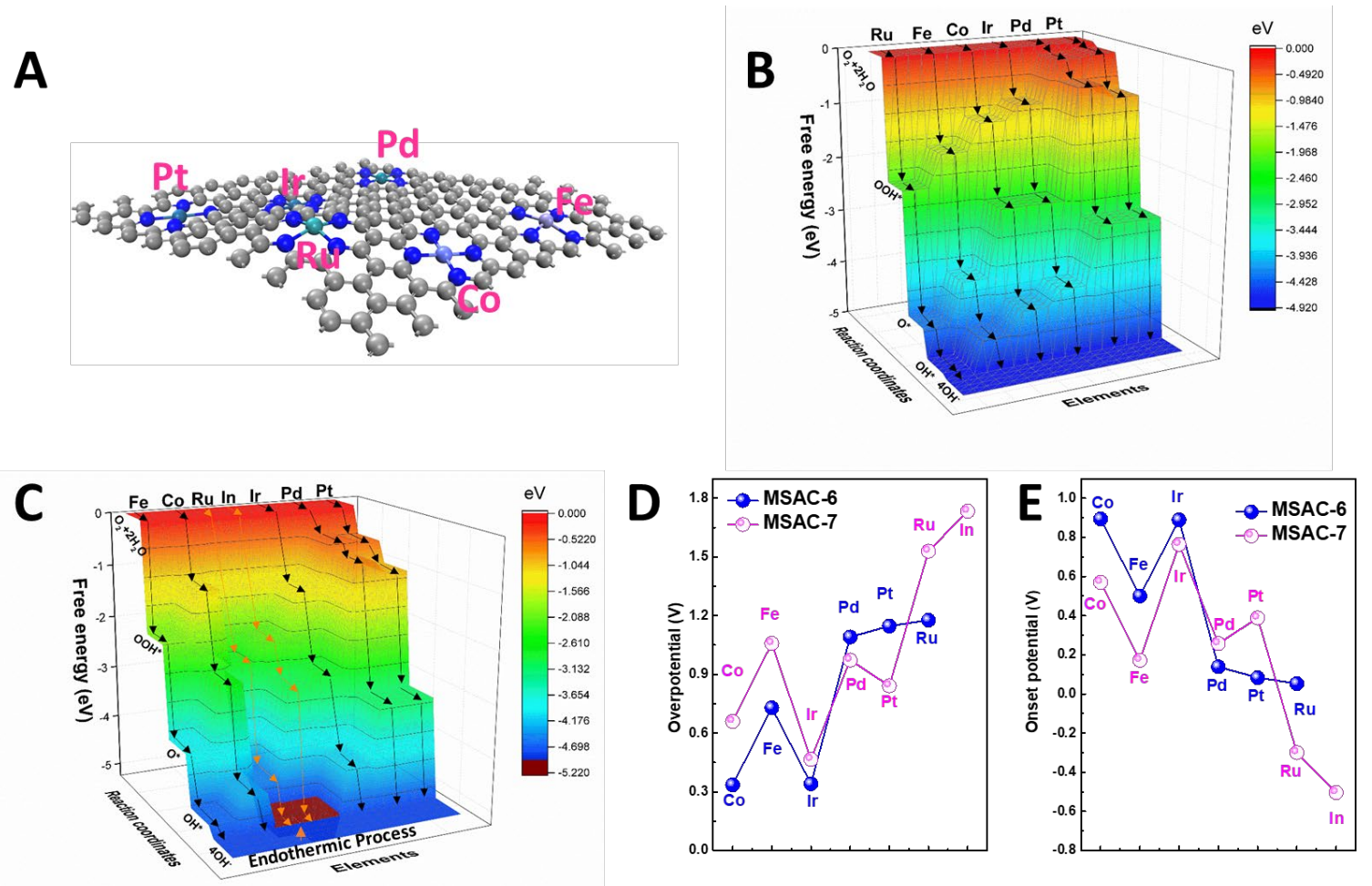

Figure 5. Theoretical calculation of MASC-6 and MSAC-7. (a) Structural illustration of MSAC-6. 3D theoretical free energy diagram for MSAC-6 (B) and MSAC-7 (C). (D) Overpotential of each single-atom unit on MSAC-6 and MSAC-7. (E) Onset potential of each single-atom unit on MSAC-6 and MSAC-7.

To investigate the synergistic effect, DFT calculations were performed on each different coordination structures of MSAC-6 and MSAC-7. The EXAFS fitting of R-space is performed for simulating their coordinated structure of each single atom of MSAC-6. As shown in Figure 5A, their simulated model of local structure suggests MSAC-6 shows a similar structure with MSAC7 (Figure 2D). Tetradentate structures, including Pt $1-4 \mathrm{~N}, \mathrm{Fe}_{1}-4 \mathrm{~N}, \mathrm{Pd}_{1}-4 \mathrm{~N}, \mathrm{Ir}_{1}-4 \mathrm{~N}, \mathrm{Ru}-4 \mathrm{~N}$, and Co$4 \mathrm{~N}$, are mainly formed on MSAC -6 (Figure S18, Table S1). The optimized structures of MSAC6 and MSAC-7 are utilized to build up the periodical surface models as it serves as the real host under ORR conditions (Figure S19 and S20). The corresponding Gibbs free energies $\left(\Delta G_{i}, i=\mathrm{OOH}^{*}, \mathrm{O}^{*}\right.$, and $\left.\mathrm{OH}^{*}\right)$ are calculated and provided (Figure $\mathrm{S} 21$ and $\mathrm{S} 22$ ). Although the local coordinated structure of MSCA-6 is highly similar to MSAC-7, it is noticeable that the combination of adjacent atoms could strongly affect the activity. For a better comparison, contour plot of 3D free energy profile can be constructed based on the calculated activities of different metal sites of MSAC-6 and MSAC-7. As shown in Figure 5B, all metal atoms on MSAC-6 show a totally exothermic process in each step, indicating their active surface for the overall $4 e^{-}$ORR. The ORR activities of MSAC-7, however, are decreased for the whole $4 e^{-}$ORR pathway by introducing the $\mathrm{In}_{1}$ single atom into the structure. The pathways for the transition from $* \mathrm{OH}$ to $\mathrm{OH}^{-}$of $\mathrm{In}_{1}$ and $\mathrm{Ru}_{1}$ are an endothermic process, indicating their inactive surface for the overall $4 e^{-}$ 
ORR (Figure 5C). This result reveals that an appropriate combination of compositions is very important for the catalytic efficiency as the introduced new atom can possibly inactivate their neighbor atoms. In particular, the ORR 3D free energy profile of MSAC-6 shows a ladder-like configuration, which means the different single atoms can serve as a key role in the conversion of different intermediates. Accordingly, the overpotential of each single atom on MSAC- 6 and MSAC-7 were summarized as shown in Figure 5D. The Co1 of MSAC shows the most energetically favourable configuration on ORR with a low overpotential of $0.33 \mathrm{~V}$. In contrast, the most active single atom $\operatorname{Ir}_{1}$ of MSAC-7 only present an overpotential of $0.46 \mathrm{~V}$. Also, the average overpotential of MSAC- 6 is $0.8 \mathrm{~V}$, which is better than that of MSAC-7 $(1.04 \mathrm{~V})$. Consequently, the onset potential of MSAC- 6 is higher than that of MSAC-7, indicating the more active surface of MSAC-6 (Figure 5E). These theoretical results are consistent with the electrochemical-test results as shown in Figure 4.

\section{Catalytic mechanism of MSAC for HER}
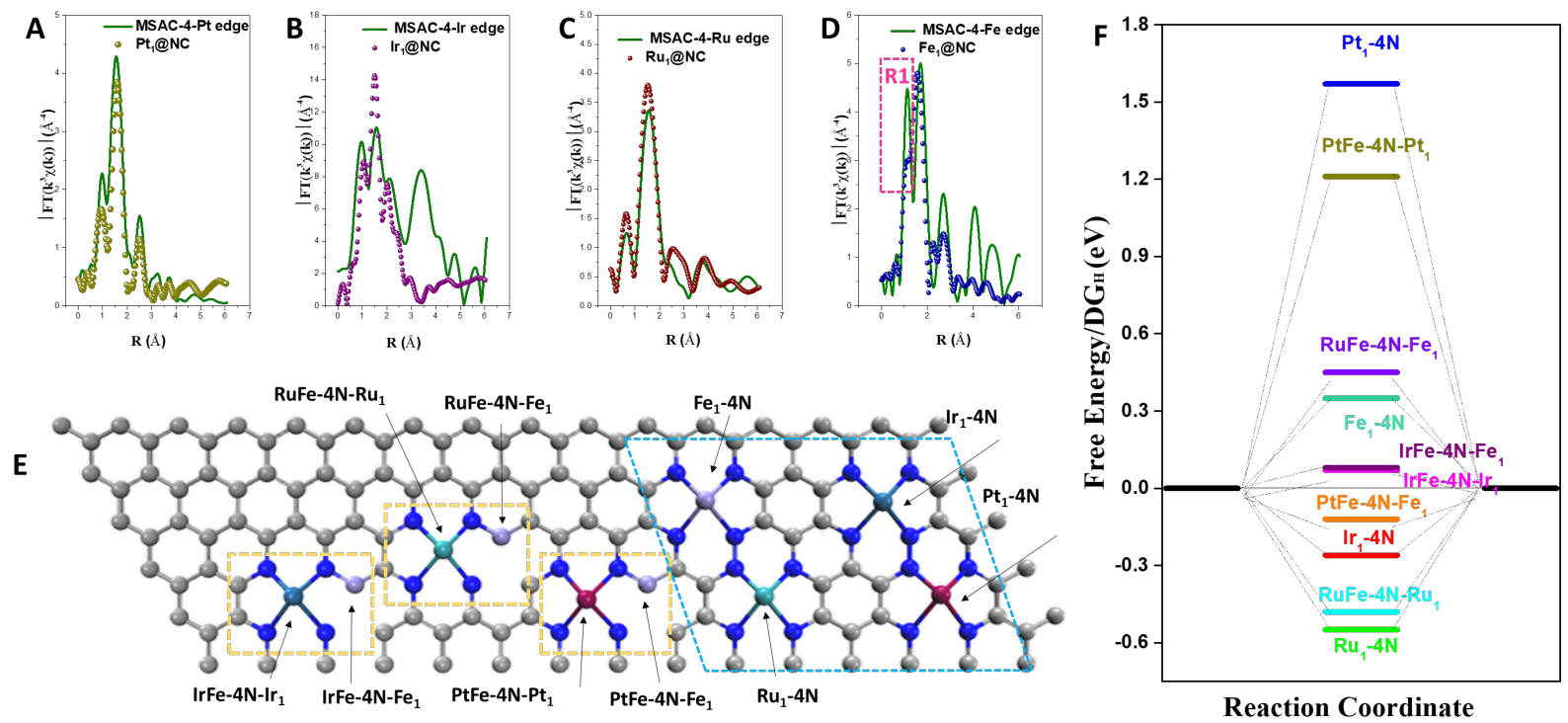

Figure 6. Structural characterization of MASC-4. (A-D) The $\mathrm{K}^{3}$-weighted Fourier transform (FT) spectra from EXAFS of samples (PtIrRuFe) $)_{1} @ N C$ and $\mathrm{Pt}_{1} @ \mathrm{NC}, \mathrm{Ir}_{1} @ \mathrm{NC}, \mathrm{Ru} \mathrm{N}_{1} @ \mathrm{NC}$, $\mathrm{Fe}_{1} @ \mathrm{NC}$ on Pt edge (A), Ir edge (B), Ru edge (C), and Fe edge (D). (E) Two parts have been considered in fitting its structure of MSAC-4. The first part is $\mathrm{Pt}_{1}, \mathrm{Ir}_{1}, \mathrm{Ru}_{1}$, and $\mathrm{Fe}_{1}$ had independent local structures, which are $\mathrm{Fe}_{1}-4 \mathrm{~N}, \mathrm{Pt}_{1}-4 \mathrm{~N}, \mathrm{Ir}_{1}-4 \mathrm{~N}$, and $\mathrm{Ru}_{1}-4 \mathrm{~N}$ (blue box). The other part we considered here is that the low-coordination has a high possibility to sit the side of precious metal groups (Pt/Ir/Ru), forming PtFe-4N-Pt1, PtFe-4N-Fe 1 , IrFe-4N-Ir 1 , IrFe-4N-Fe1, RuFe-4N-Ru1 and $\mathrm{RuFe}-4 \mathrm{~N}-\mathrm{Fe}_{1}$ (yellow box). (F) The free energy diagrams for the HER on $\mathrm{Pt}_{1}-4 \mathrm{~N}, \mathrm{Ir}_{1}-4 \mathrm{~N}, \mathrm{Ru}_{1}-4 \mathrm{~N}$, $\mathrm{Fe}_{1}-4 \mathrm{~N}, \mathrm{PtFe}-4 \mathrm{~N}-\mathrm{Pt}_{1}$, IrFe-4N-Ir 1 , RuFe-4N-Ru ${ }_{1}, \mathrm{PtFe}-4 \mathrm{~N}-\mathrm{Fe}_{1}, \mathrm{IrFe}-4 \mathrm{~N}-\mathrm{Fe}_{1}, \mathrm{RuFe}-4 \mathrm{~N}-\mathrm{Fe}_{1}$.

The optimal MASC-4 for HER was selected as an example to have detailed structural characterization and theoretical calculation. The previous reports have been experimentally and theoretically confirmed that the co-dopants of non-metal elements, such as boron, nitrogen, phosphorus, and sulphur, were able to increase the HER capability due to the synergistic effect between doped elements. ${ }^{32}$ Our analysis also suggest that the co-doped single-atom metals can synergistically enhance the HER performance via favourable combination of elements. According 
to the XAS results, the single atoms $\mathrm{Pt}_{1}, \mathrm{Ir}_{1}$ and $\mathrm{Ru}_{1}$ on sample MSAC-4 are likely to have a similar atomic coordination with $\mathrm{Pt}_{1} @ \mathrm{NC}, \mathrm{Ir}_{1} @ \mathrm{NC}$, and $\mathrm{Ru} \mathrm{u}_{1} @ \mathrm{NC}$ due to the highly overlapped EXAFS spectra on the first shell as shown in Figure 6A-C. In contrast, the further doped Fe 1 single atoms on MSAC-4 have a strong low coordination peak, which is indicated by rectangle R1 (Figure 6D). These low coordinated $\mathrm{Fe}_{1}$ structure suggests that $\mathrm{Fe}_{1}$ can sit along with $\mathrm{Pt}_{1}$, $\mathrm{Ir}_{1}$, and $\mathrm{Ru}$ 1, leading to a strong correlation among these atoms, although parts of single $\mathrm{Fe}_{1}$ single atoms also formed a same shell with $\mathrm{Fe}_{1} @ \mathrm{NC}$. In order to confirm the synergistic effect between different metal atoms, the fitting of EXAFS spectra on MSAC-4 are performed. Based on the EXAFS spectra and our simulated structural models, the single atoms $\mathrm{Pt}_{1}, \mathrm{Ir}_{1}$ and $\mathrm{Ru}_{1}$ on MSAC-4 are prone to form $\mathrm{Pt}_{1}$ $4 \mathrm{~N}, \mathrm{Ir}_{1}-4 \mathrm{~N}$ and $\mathrm{Ru}_{1}-4 \mathrm{~N}$ structures (Figure S23). In contrast, the doped $\mathrm{Fe}_{1}$ single atoms on MSAC4 have a strong low coordination peak and a high coordination peak, which is corresponding to $\mathrm{Fe}_{1}-4 \mathrm{~N}$ and $\mathrm{Fe}_{1}-1 \mathrm{~N} 1 \mathrm{C}$ (Figure S24), respectively. These low coordinated Fe1-1N1C is subject to sit along with $\mathrm{Pt}_{1}, \mathrm{Ir}_{1}$, and $\mathrm{Ru}_{1}$, leading to strong interaction with these atoms as illuminated in Figure 6E. Also, the high resolution of FFTI-HAADF images of MSAC-4 show that the Fe atom (low contrast) has a high possibility to sit the side of precious metal groups ( $\mathrm{Pt} / \mathrm{Ir} / \mathrm{Ru}$ ) (high contrast), forming PtFe-4N, IrFe-4N, and RuFe-4N (Figure S25). The density functional theory (DFT) calculation also was used to confirm our hypothesis. Based on the fitting models of MSAC4, the corresponding active units, including $\mathrm{Fe}_{1}-4 \mathrm{~N}, \mathrm{Pt}_{1}-4 \mathrm{~N}, \mathrm{Ir}_{1}-4 \mathrm{~N}, \mathrm{Ru} \mathrm{u}_{1}-4 \mathrm{~N}, \mathrm{PtFe}-4 \mathrm{~N}-\mathrm{Pt}_{1}, \mathrm{PtFe}-$ $4 \mathrm{~N}-\mathrm{Fe}_{1}, \mathrm{IrFe}-4 \mathrm{~N}-\mathrm{Ir}_{1}, \mathrm{IrFe}-4 \mathrm{~N}-\mathrm{Fe}_{1}, \mathrm{RuFe}-4 \mathrm{~N}-\mathrm{Ru}{ }_{1}$ and $\mathrm{RuFe}-4 \mathrm{~N}-\mathrm{Fe}_{1}$, were constructed (Figure $\mathrm{S} 26)$. As shown in Figure 6F, the active sites of PtFe-4N-Pt 1 (1.21 eV), IrFe-4N-Ir 1 (0.07 eV), and RuFe-4N-Ru $(-0.48 \mathrm{eV})$ on MSAC-4 show more favourable HER activity (closer to zero) due to the co-doped Fe on side, compared to their independent status of $\mathrm{Pt}_{1}-4 \mathrm{~N}(1.57 \mathrm{eV}), \operatorname{Ir}_{1}-4 \mathrm{~N}(-0.33$ $\mathrm{eV})$, and $\mathrm{Ru}_{1}-4 \mathrm{~N}(-0.49 \mathrm{eV})$. In turn, PtFe-4N-Fe $(-0.12 \mathrm{eV})$ and $\mathrm{IrFe}-4 \mathrm{~N}-\mathrm{Fe}_{1}(0.08 \mathrm{eV})$ exhibit better HER activity than $\mathrm{Fe}_{1}-4 \mathrm{~N}(0.35 \mathrm{eV})$, indicating that the synergistic effects from $\mathrm{Pt}_{1}$, and $\mathrm{Ir}_{1}$ increase the HER capability of the neighbour Fe single atom. However, RuFe-4N-Fe $(0.45 \mathrm{eV})$ have a minor fade. Our hypothesis is speculated by assuming that all these active sites have an average ratio. The actual ratios of individual dual active sites, however, are challenging to quantitate. The synergistic effects between variable elements on MSAC, thus, are supposed to change their intrinsic electronic structure as well as the catalytic ability.

In summary, based on an anion doped polymer, a versatile tactic is explored to flexibly tune the complexity of carbon surface from mono- to multi-metallic single atom doping. As a result, several active sites can coexist on carbon support, enriching the structural complexity and catalytic chemistry of SACs. In particular, MSAC-6 illustrates an ultrahigh mass activity for ORR compared to the results reported previously. We demonstrates that the atomic-level cooperative interactions in multimetallic SACs directly determine the overall material properties as well as catalytic activity. Also, we concludes that an appropriate combination of compositions on carbon surface can maximize the catalytic efficiency. Our results extend the boundary of SACs and thus, open a new avenue to a range of catalysts in terms of the atomic control of surface complexity and subsequent enhancement of catalytic activity. The high complexity and disordered structure of carbon surface derived from multi-single-atom doping, however, is very complicated and challenging, extraordinary efforts should be devoted to unveil their underlying mechanism on catalytic reactions. 


\section{Methods and materials}

\section{Materials}

Sodium p-toluenesulfonate $\left(\mathrm{CH}_{3} \mathrm{C}_{6} \mathrm{H}_{4} \mathrm{SO}_{3} \mathrm{Na}, 97 \%\right.$, P-TSNa), Vanadium(III) chloride (VCl 3 , 97\%), Manganese sulfate monohydrate $\left(\mathrm{MnSO}_{4} \cdot \mathrm{H}_{2} \mathrm{O}, 99 \%\right)$, Silver nitrate $\left(\mathrm{AgNO}_{3}, 99 \%\right)$, Germanium(II) chloride ( $\mathrm{GeCl}_{2}, 99 \%$ ), Tungsten(IV) chloride ( $\left.\mathrm{WCl}_{4}, 95 \%\right)$, Tin(II) chloride $\left(\mathrm{SnCl}_{2}, 98 \%\right)$, Rhodium(III) acetylacetonate $\left(\mathrm{C}_{15} \mathrm{H}_{21} \mathrm{O}_{6} \mathrm{Rh}, 97 \%\right)$, Cobalt(III) acetylacetonate $\left(\mathrm{C}_{15} \mathrm{H}_{21} \mathrm{O}_{6} \mathrm{Co}\right)$, Platinum(II) acetylacetonate $\left(\mathrm{C}_{10} \mathrm{H}_{14} \mathrm{O}_{4} \mathrm{Pt}, 99 \%\right)$, Iridium(II) acetylacetonate $\left(\mathrm{C}_{10} \mathrm{H}_{14} \mathrm{O}_{4} \mathrm{Ir}\right.$, 99\%), Palladium(II) acetylacetonate $\left(\mathrm{C}_{10} \mathrm{H}_{14} \mathrm{O}_{4} \mathrm{Pd}, 99 \%\right)$, Lead(II) chloride $\left(\mathrm{PbCl}_{2}\right.$, $98 \%$ ), Bismuth(III) nitrate pentahydrate $\left(\mathrm{Bi}\left(\mathrm{NO}_{3}\right)_{3} \cdot 5 \mathrm{H}_{2} \mathrm{O}, 97 \%\right)$, Ruthenium (III) acetylacetonate $\left(\mathrm{C}_{15} \mathrm{H}_{21} \mathrm{O}_{6} \mathrm{Ru}, 97 \%\right)$, Iron (III) acetylacetonate $\left(\mathrm{C}_{15} \mathrm{H}_{21} \mathrm{O}_{6} \mathrm{Fe}, 99 \%\right)$, Nickel (II) acetylacetonate $\left(\mathrm{C}_{10} \mathrm{H}_{14} \mathrm{O}_{4} \mathrm{Ni}, 99 \%\right)$, Molybdenum(V) isopropoxide $\left(\mathrm{C}_{15} \mathrm{H}_{35} \mathrm{MoO}_{5}, 99 \%\right)$, Copper sulfate $\left(\mathrm{CuSO}_{4}\right.$, 99\%), Indium(III) chloride ( $\mathrm{InCl}_{3}, 98 \%$ ), Nafion@117 solution (5 wt \%, dispersed in a binary solvent of water and lower aliphatic alcohols), commercial Pt black (20 wt. \% Pt loading on Vulcan $\mathrm{XC72).} \mathrm{All} \mathrm{the} \mathrm{chemical} \mathrm{reagents} \mathrm{were} \mathrm{used} \mathrm{as} \mathrm{received} \mathrm{without} \mathrm{any} \mathrm{further} \mathrm{purification.}$

\section{Synthesis of S-PPy}

In a typical synthesis, S-PPy was prepared by oxidation polymerization reaction. The oxidant ammonia persulfate $\left(1.13 \mathrm{~g}\right.$ ) was dissolved in $20 \mathrm{ml} \mathrm{H}_{2} \mathrm{O}$, and added slowly under stirring into 200 $\mathrm{mL} 1 \mathrm{M}$ hydrochloride acid containing $0.33 \mathrm{~g}$ pyrrole monomer and $0.25 \mathrm{~g}$ P-TSNa. The polymerization was carried out at $0-5{ }^{\circ} \mathrm{C}$ for $24 \mathrm{~h}$. The precipitate was washed for several times with deionized water till the filtrate became neutral, and further washed with ethanol and acetone for several times. The resulting powder was dried overnight at $80{ }^{\circ} \mathrm{C}$ in a vacuum oven. The compared PPy were prepared in the similar way with S-PPy but without P-TSNa.

\section{Synthesis of MSAC.}

In a typical synthesis, $50 \mathrm{mg}$ S-PPy powders were mixed with $50 \mathrm{ml}$ ethanol by ultra-sonification for $30 \mathrm{~min}$ to form a homogeneous dispersion. A mixture of metal salts $\left(\mathrm{C}_{10} \mathrm{H}_{14} \mathrm{O}_{4} \mathrm{Pt}(0.0015\right.$ mmol), $\mathrm{C}_{15} \mathrm{H}_{21} \mathrm{O}_{6} \mathrm{Co}(0.003 \mathrm{mmol}), \mathrm{C}_{10} \mathrm{H}_{14} \mathrm{O}_{4} \mathrm{Pd}(0.0015 \mathrm{mmol}), \mathrm{C}_{10} \mathrm{H}_{14} \mathrm{O}_{4} \mathrm{Ir}$ (0.0015 mmol), $\left.\mathrm{C}_{15} \mathrm{H}_{21} \mathrm{O}_{6} \mathrm{Fe}(0.003 \mathrm{mmol}), \mathrm{InCl}_{3}(0.0010 \mathrm{mmol}), \mathrm{C}_{15} \mathrm{H}_{21} \mathrm{O}_{6} \mathrm{Ru}(0.0015 \mathrm{mmol})\right)$ were then added into the dispersion, with rigorously stirring until the ethanol evaporated out, forming S-PPy$\mathrm{M}_{\text {mixture }}{ }^{\mathrm{x}}$ mixtures. Finally, the mixtures were annealed at $750{ }^{\circ} \mathrm{C}$ under argon for $2 \mathrm{~h}$. These resultant products were denoted as MSAC-7. Similarly, the MSAC-6, MSAC-5, MSAC-4, MSAC3 , and MSAC-2 were prepared in a same way of MSAC-7 by using their corresponding mixture of designable elements, which have a same concentration with the metal salts of MSAC-7.

\section{Synthesis of $M_{1} @ N C$.}

In a typical synthesis, $50 \mathrm{mg}$ PPy powders were mixed with $50 \mathrm{ml}$ ethanol by ultra-sonification for $30 \mathrm{~min}$ to form a homogeneous dispersion. $0.0075 \mathrm{mmol}$ metal salts were then added into the dispersion, with rigorously stirring until the ethanol evaporated out, forming S-PPy-M $\mathrm{M}^{\mathrm{x+}}$ mixtures, respectively. Finally, the mixtures were annealed at $750{ }^{\circ} \mathrm{C}$ under argon for $2 \mathrm{~h}$. These resultant products were denoted as $\mathrm{M}_{1} @ \mathrm{NC}$, respectively.

\section{Characterization.}

High-angle annular dark-field - scanning transmission electron microscope (HAADF-STEM) images, EELS image and STEM energy dispersive X-ray spectroscopy (STEM-EDS) data were acquired on a transmission electron microscopy system (TEM, JEOL ARM-200F, $200 \mathrm{kV}$ ). The XRD patterns were collected by powder X-ray diffraction (XRD; GBC MMA diffractometer) with $\mathrm{Cu} \mathrm{K} \alpha$ radiation at a scan rate of $3^{\circ} \mathrm{min}^{-1}$. The bonding on $\mathrm{Pt}_{1} @ \mathrm{Co} / \mathrm{CN}$ was determined by X-ray photoelectron spectroscopy (XPS; PHOIBOS 100 Analyser from SPECS, Berlin, Germany; Al K $\alpha$ $\mathrm{X}$-rays). The loading mass was determined by inductively coupled plasma - optical emission 
spectrometry (ICP-AES, IRIS Intrepid ER/S, Thermo Elemental). Fourier transform infrared spectroscopy (FTIR) was performed at room temperature on a Shimadzu Prestige-21. Raman spectroscopy was used to determine the length of bonds on a Jobin Yvon HR800. X-ray absorption spectroscopy (XAS) experiments were carried out at the applied X-ray absorption fine structure spectroscopy (XAFS) at Japan Synchrotron Radiation Research Institute (JASRI) (1-1-1, Kouto, Sayo-cho, Sayo-gun, Hyogo 679-5198 Japan).

\section{Electrochemical Measurements.}

Before the glassy carbon electrode (GCE) was used for rotating disk electrode (RDE) measurements, it was consecutively polished with 1.0 and $0.05 \mu \mathrm{m}$ alumina powder, rinsed with deionized water, and sonicated first in ethanol and then in water. Typically, working electrodes were prepared by mixing the catalyst with deionized water + isopropanol $+5 \%$ Nafion ${ }^{\circledR}(\mathrm{v} / \mathrm{v} / \mathrm{v}=$ 4/1/0.05). The loading mass on the rotating disk electrode (RDE) was calculated as $100.2 \mu \mathrm{g} \mathrm{cm}^{-}$ 2. A graphite electrode was used as the counter electrode, and $\mathrm{Ag} / \mathrm{AgCl}(\mathrm{KCl}, 3 \mathrm{M})$ was used as the reference electrode, with all potentials referred to reversible hydrogen electrode (RHE). Thus, the potential with respect to RHE can be calculated as follows: $E(\mathrm{RHE})=E(\mathrm{Ag} / \mathrm{AgCl})+0.059 \times \mathrm{pH}$ +0.210 . Before testing, flowing $\mathrm{N}_{2}$ was bubbled through the electrolyte in the cell to achieve an $\mathrm{N}_{2}$-saturated solution. The ORR tests were carried out in $0.1 \mathrm{M} \mathrm{KOH}$ by using a computercontrolled potentiostat (Princeton 2273 and 616, Princeton Applied Research) in a conventional three-electrode cell at room temperature. Before testing, flowing $\mathrm{N}_{2} / \mathrm{O}_{2}$ was bubbled through the electrolyte in the cell to achieve an $\mathrm{N}_{2} / \mathrm{O}_{2}$-saturated solution. The oxygen reduction reaction (ORR) testing was carried out in $\mathrm{O}_{2}$-saturated $0.1 \mathrm{M} \mathrm{KOH}$ solution at different rotation rates with a scan rate of $10 \mathrm{mV} \mathrm{s}^{-1}$. Accelerated durability tests were performed at room temperature in $\mathrm{O}_{2}$-saturated $0.1 \mathrm{M} \mathrm{KOH}$ solution by applying cyclic potential sweeps between 0.6 and $1.0 \mathrm{~V}$ versus RHE at a scan rate of $50 \mathrm{mV} \mathrm{s}^{-1}$ for 10000 cycles. The kinetic current $\left(I_{k}\right)$ can be calculated using the Koutecky-Levich (K-L) equation, which is expressed by

$$
\frac{1}{I}=\frac{1}{I_{k}}+\frac{1}{I_{d}}
$$

where $I$ is the measured current and $I_{d}$ the diffusion limited current.

The K-L plot is based on the Levich equation:

$$
I_{d}=0.62 n F A D^{2 / 3} v^{-1 / 6} \omega^{1 / 2} C_{O_{2}}
$$

where $n$ is the number of electrons transferred; $F$ is Faraday's constant; $A$ is the area of the electrode $\left(0.196 \mathrm{~cm}^{2}\right) ; D$ is the diffusion coefficient of $\mathrm{O}_{2}$ in $0.1 \mathrm{M} \mathrm{KOH} ; v$ is the kinematic viscosity of the electrolyte; $\omega$ is the angular frequency of rotation, $\omega=2 \pi f / 60$, where $f$ is the RDE rotation rate in rpm and $C_{\mathrm{O}_{2}}$ is the concentration of molecular oxygen in $0.1 \mathrm{M} \mathrm{KOH}$ solution. The HER tests were carried out in $\mathrm{N}_{2}$-saturated $1 \mathrm{M} \mathrm{KOH}$ solution with a scan rate of $10 \mathrm{mV} \mathrm{s}^{-1}$.

\section{Computational details.}

All calculations were performed by the spin-polarized density functional theory (DFT) methods as implemented in the Vienna Ab initio Simulation Package (VASP) ${ }^{33-34}$. The Perdew-BurkeErnzerhof (PBE) exchange-correlation functional within a generalized gradient approximation (GGA) was employed, and a $400 \mathrm{eV}$ cutoff energy for the plane-wave basis set was used for the valence electrons. The convergence threshold was $10^{-5} \mathrm{eV}$ for energy and $0.02 \mathrm{eV} / \AA$ for force, respectively.

To simulate a defective graphene monolayer, a periodic $4 \times 4$ supercell was built. To avoid the interactions between two adjacent periodic images, the vacuum thickness was set to be $20 \AA$. The Brillouin zone was sampled using the $3 \times 3 \times 1$ Monkhorst-Pack k-point mesh in structure 
optimization, and the semiempirical dispersion-corrected DFT force-field approach (DFT-D3) ${ }^{35}$ was adopted to describe the interaction involved in the calculations.

The $\Delta \mathrm{G}$ value can be determined as: $\Delta \mathrm{G}=\Delta \mathrm{E}+\Delta \mathrm{zPE}-\mathrm{T} \Delta \mathrm{S}+\Delta \mathrm{Gu}+\Delta \mathrm{G}_{\mathrm{pH}}$, where $\Delta \mathrm{E}$ is the difference in electron energy obtained directly from the DFT calculation, $\triangle Z P E$ is the change in zero-point energies, $\mathrm{T}$ is the temperature $(\mathrm{T}=298.15 \mathrm{~K})$, and $\Delta \mathrm{S}$ is the entropy change. $\Delta \mathrm{Gu}$ is the free energy contribution related to electrode potential $\mathrm{U} . \Delta \mathrm{G}_{\mathrm{pH}}$ is the correction of the $\mathrm{H}^{+}$free energy by the concentration, which can be determined as $\Delta \mathrm{G}_{\mathrm{pH}}=2.303 \times \mathrm{kBT} \times \mathrm{pH}$ (or $0.059 \times$ $\mathrm{pH})$, where $\mathrm{k}_{\mathrm{B}}$ is the Boltzmann constant.

For ORR, The change in Gibbs free energy $(\Delta G)$ of the various intermediates was expressed as:

$$
\Delta G=\Delta E+\Delta \mathrm{ZPE}-T \Delta S
$$

where $\Delta \mathrm{E}$ is the reaction energy of the elementary steps, $\Delta \mathrm{ZPE}$ is the zero point energy change, $T$ is the temperature at $298.15 \mathrm{~K}$, and $\Delta S$ is the entropy change. $\Delta \mathrm{ZPE}$ and $\Delta S$ could be obtained from calculations of the vibrational frequency of intermediates and gas phase species, which were obtained from the NIST database. $\mathrm{H}_{2} \mathrm{O}$ and $\mathrm{H}_{2}$ can be well described within the framework of DFT calculations. The entropy of gas-phase water was calculated to be 0.035 bar which is due to the equilibrium pressure at room temperature. The free energy change is fixed at the experimental value of $2.46 \mathrm{eV}$ for the total reaction: $\mathrm{H}_{2} \mathrm{O} \rightarrow 1 / 2 \mathrm{O}_{2}+\mathrm{H}_{2}$. So, the free energy of $\mathrm{O}_{2}$ can be obtained from $G\left(\mathrm{O}_{2}\right)=4.92+2\left(G\left(\mathrm{H}_{2} \mathrm{O}\right)-G\left(\mathrm{H}_{2}\right)\right)$.

\section{References}

1. Fei, H.; Dong, J.; Feng, Y.; Allen, C. S.; Wan, C.; Volosskiy, B.; Li, M.; Zhao, Z.; Wang, Y.; Sun, H., General synthesis and definitive structural identification of MN 4 C 4 single-atom catalysts with tunable electrocatalytic activities. Nature Catalysis 2018, 1 (1), 63.

2. $\quad$ Lai, W. H.; Miao, Z.; Wang, Y. X.; Wang, J. Z.; Chou, S. L., Atomic-Local Environments of Single-Atom Catalysts: Synthesis, Electronic Structure, and Activity. Advanced Energy Materials 2019.

3. Gong, K.; Du, F.; Xia, Z.; Durstock, M.; Dai, L., Nitrogen-doped carbon nanotube arrays with high electrocatalytic activity for oxygen reduction. science 2009, 323 (5915), 760-764.

4. Kim, D.-w.; Li, O. L.; Saito, N., Enhancement of ORR catalytic activity by multiple heteroatom-doped carbon materials. Physical Chemistry Chemical Physics 2015, 17 (1), 407-413.

5. Daelman, N.; Capdevila-Cortada, M.; López, N., Dynamic charge and oxidation state of $\mathrm{Pt} / \mathrm{CeO} 2$ single-atom catalysts. Nature materials 2019.

6. Jones, J.; Xiong, H.; DeLaRiva, A. T.; Peterson, E. J.; Pham, H.; Challa, S. R.; Qi, G.; Oh, S.; Wiebenga, M. H.; Hernández, X. I. P., Thermally stable single-atom platinum-on-ceria catalysts via atom trapping. Science 2016, 353 (6295), 150-154.

7. Wei, H.; Liu, X.; Wang, A.; Zhang, L.; Qiao, B.; Yang, X.; Huang, Y.; Miao, S.; Liu, J.; Zhang, T., FeO X-supported platinum single-atom and pseudo-single-atom catalysts for chemoselective hydrogenation of functionalized nitroarenes. Nature communications 2014, 5 , 5634.

8. $\quad$ Zhang, Z.; Zhu, Y.; Asakura, H.; Zhang, B.; Zhang, J.; Zhou, M.; Han, Y.; Tanaka, T.; Wang, A.; Zhang, T., Thermally stable single atom Pt/m-Al 2 O 3 for selective hydrogenation and CO oxidation. Nature communications 2017, 8, 16100.

9. Lucci, F. R.; Liu, J.; Marcinkowski, M. D.; Yang, M.; Allard, L. F.; FlytzaniStephanopoulos, M.; Sykes, E. C. H., Selective hydrogenation of 1, 3-butadiene on platinumcopper alloys at the single-atom limit. Nature communications 2015, 6, 8550. 
10. Cheng, N.; Stambula, S.; Wang, D.; Banis, M. N.; Liu, J.; Riese, A.; Xiao, B.; Li, R.; Sham, T.-K.; Liu, L.-M., Platinum single-atom and cluster catalysis of the hydrogen evolution reaction. Nature communications 2016, 7, 13638.

11. Ou, M.; Wan, S.; Zhong, Q.; Zhang, S.; Wang, Y., Single Pt atoms deposition on g-C3N4 nanosheets for photocatalytic $\mathrm{H} 2$ evolution or NO oxidation under visible light. International Journal of Hydrogen Energy 2017, 42 (44), 27043-27054.

12. Yin, P.; Yao, T.; Wu, Y.; Zheng, L.; Lin, Y.; Liu, W.; Ju, H.; Zhu, J.; Hong, X.; Deng, Z., Single cobalt atoms with precise $\mathrm{N}$-coordination as superior oxygen reduction reaction catalysts. Angewandte chemie international edition 2016, 55 (36), 10800-10805.

13. Chen, P.; Zhou, T.; Xing, L.; Xu, K.; Tong, Y.; Xie, H.; Zhang, L.; Yan, W.; Chu, W.; Wu, C., Atomically dispersed iron-nitrogen species as electrocatalysts for bifunctional oxygen evolution and reduction reactions. Angewandte Chemie International Edition 2017, 56 (2), 610614.

14. Qiao, B.; Wang, A.; Yang, X.; Allard, L. F.; Jiang, Z.; Cui, Y.; Liu, J.; Li, J.; Zhang, T., Single-atom catalysis of $\mathrm{CO}$ oxidation using Pt 1/FeO x. Nature chemistry 2011, 3 (8), 634.

15. Gao, G.; Jiao, Y.; Waclawik, E. R.; Du, A., Single atom (Pd/Pt) supported on graphitic carbon nitride as an efficient photocatalyst for visible-light reduction of carbon dioxide. Journal of the American Chemical Society 2016, 138 (19), 6292-6297.

16. Tao, H.; Choi, C.; Ding, L.-X.; Jiang, Z.; Han, Z.; Jia, M.; Fan, Q.; Gao, Y.; Wang, H.; Robertson, A. W., Nitrogen fixation by Ru single-atom electrocatalytic reduction. Chem 2019, 5 (1), 204-214.

17. Zang, W.; Sumboja, A.; Ma, Y.; Zhang, H.; Wu, Y.; Wu, S.; Wu, H.; Liu, Z.; Guan, C.; Wang, J., Single Co Atoms Anchored in Porous N-Doped Carbon for Efficient Zinc- Air Battery Cathodes. ACS Catalysis 2018, 8 (10), 8961-8969.

18. Du, Z.; Chen, X.; Hu, W.; Chuang, C.; Xie, S.; Hu, A.; Yan, W.; Kong, X.; Wu, X.; Ji, H., Cobalt in Nitrogen-Doped Graphene as Single-Atom Catalyst for High-Sulfur Content LithiumSulfur Batteries. Journal of the American Chemical Society 2019, 141 (9), 3977-3985.

19. Zhang, B.-W.; Sheng, T.; Liu, Y.-D.; Wang, Y.-X.; Zhang, L.; Lai, W.-H.; Wang, L.; Yang, J.; Gu, Q.-F.; Chou, S.-L., Atomic cobalt as an efficient electrocatalyst in sulfur cathodes for superior room-temperature sodium-sulfur batteries. Nature communications 2018, 9 (1), 4082.

20. Guo, X.; Fang, G.; Li, G.; Ma, H.; Fan, H.; Yu, L.; Ma, C.; Wu, X.; Deng, D.; Wei, M., Direct, nonoxidative conversion of methane to ethylene, aromatics, and hydrogen. Science 2014, 344 (6184), 616-619.

21. Lin, L.; Zhou, W.; Gao, R.; Yao, S.; Zhang, X.; Xu, W.; Zheng, S.; Jiang, Z.; Yu, Q.; Li, Y.-W., Low-temperature hydrogen production from water and methanol using $\mathrm{Pt} / \alpha-\mathrm{MoC}$ catalysts. Nature 2017, 544 (7648), 80.

22. Wang, A.; Li, J.; Zhang, T., Heterogeneous single-atom catalysis. Nature Reviews Chemistry 2018, 2 (6), 65.

23. Lee, B.-H.; Park, S.; Kim, M.; Sinha, A. K.; Lee, S. C.; Jung, E.; Chang, W. J.; Lee, K.-S.; Kim, J. H.; Cho, S.-P., Reversible and cooperative photoactivation of single-atom $\mathrm{Cu} / \mathrm{TiO} 2$ photocatalysts. Nature materials 2019, 18 (6), 620.

24. Chen, M.; Goodman, D., The structure of catalytically active gold on titania. science 2004, 306 (5694), 252-255.

25. Sun, S.; Zhang, G.; Gauquelin, N.; Chen, N.; Zhou, J.; Yang, S.; Chen, W.; Meng, X.; Geng, D.; Banis, M. N., Single-atom catalysis using Pt/graphene achieved through atomic layer deposition. Scientific reports 2013, 3, 1775. 
26. He, X.; He, Q.; Deng, Y.; Peng, M.; Chen, H.; Zhang, Y.; Yao, S.; Zhang, M.; Xiao, D.; Ma, D., A versatile route to fabricate single atom catalysts with high chemoselectivity and regioselectivity in hydrogenation. Nature communications 2019, 10 (1), 1-9.

27. Yang, H.; Shang, L.; Zhang, Q.; Shi, R.; Waterhouse, G. I.; Gu, L.; Zhang, T., A universal ligand mediated method for large scale synthesis of transition metal single atom catalysts. Nature Communications 2019, 10 (1), 1-9.

28. Zhang, L.; Fischer, J. M. T. A.; Jia, Y.; Yan, X.; Xu, W.; Wang, X.; Chen, J.; Yang, D.; Liu, H.; Zhuang, L.; Hankel, M.; Searles, D. J.; Huang, K.; Feng, S.; Brown, C. L.; Yao, X., Coordination of Atomic Co-Pt Coupling Species at Carbon Defects as Active Sites for Oxygen Reduction Reaction. Journal of the American Chemical Society 2018, 140 (34), 10757-10763.

29. Liu, R.; Iddir, H.; Fan, Q.; Hou, G.; Bo, A.; Ley, K. L.; Smotkin, E.; Sung, Y.-E.; Kim, H.; Thomas, S., Potential-dependent infrared absorption spectroscopy of adsorbed $\mathrm{CO}$ and X-ray photoelectron spectroscopy of arc-melted single-phase Pt, PtRu, PtOs, PtRuOs, and Ru electrodes. The Journal of Physical Chemistry B 2000, 104 (15), 3518-3531.

30. Teliska, M.; O'Grady, W.; Ramaker, D., Determination of $\mathrm{H}$ adsorption sites on $\mathrm{Pt} / \mathrm{C}$ electrodes in $\mathrm{HClO} 4$ from Pt L23 X-ray absorption spectroscopy. The Journal of Physical Chemistry B 2004, 108 (7), 2333-2344.

31. Nørskov, J. K.; Rossmeisl, J.; Logadottir, A.; Lindqvist, L.; Kitchin, J. R.; Bligaard, T.; Jonsson, H., Origin of the overpotential for oxygen reduction at a fuel-cell cathode. The Journal of Physical Chemistry B 2004, 108 (46), 17886-17892.

32. Jiao, Y.; Zheng, Y.; Davey, K.; Qiao, S.-Z., Activity origin and catalyst design principles for electrocatalytic hydrogen evolution on heteroatom-doped graphene. Nature Energy 2016, 1, 16130.

33. Kresse, G.; Furthmüller, J., Efficient iterative schemes for ab initio total-energy calculations using a plane-wave basis set. Physical review B 1996, 54 (16), 11169.

34. Kresse, G.; Joubert, D., From ultrasoft pseudopotentials to the projector augmented-wave method. Physical Review B 1999, 59 (3), 1758.

35. Grimme, S., Semiempirical GGA-type density functional constructed with a long-range dispersion correction. Journal of computational chemistry 2006, 27 (15), 1787-1799.

\section{Acknowledgments}

This work is financially supported by the Australian Research Council (ARC) (DE170100928), and Australian Renewable Energy Agency (ARENA) Project (G00849). We thank the UOW Electron Microscopy Centre for use of the facilities (LE0882813 and LE0237478) and Dr. Tania Silver for critical reading of the manuscript. We also thank Lin Li, Li Wang, and Min Liu for their help in characterization. The synchrotron radiation experiments were performed at Japan Atomic Energy Agency (JAEA) beamline BL14B1 in SPring-8 (Proposal Nos. 2018A3634 and 2018B3634) under the Shared Use Program of JAEA Facilities (Proposal Nos. 2018A-E01 and 2018B-E01) with the approval of the Nanotechnology Platform project supported by the Ministry of Education, Culture, Sports, Science and Technology (Proposal Nos. A-18-AE-0001 and A-18AE-0023).

\section{Author contributions}

W.H.L., Y.-X. W., L. W., S.- L. C. designed the experiments. W.-H. L. and W.Z. synthesized the samples. H. W., H. Y., L.F.Z. and D. M. performed XAS experiments and analysed the results. H.W.L., Y.J.L., and Z.C.Y. done FTRI and Raman characterization. Q. J. and Q. S. performed the 
ab initio calculations. The project was planned, directed and supervised by J.Z.W., H.-K. L., S.-L. C. L. W., and S.-X. D. All authors discussed the results and contributed to manuscript preparation.

\section{Competing interests}

The authors declare no competing interests.

\section{Additional information}

Supplementary information:

Supplementary Figs. S1-26, Tables 1-3 


\section{Supplementary Materials for}

\section{Tunable carbon surface from mono- to multi-metallic single atoms}

Wei-Hong Lai, ${ }^{1,2,3}$ Heng Wang, ${ }^{4}$ Zi-Chao Yan, ${ }^{3}$ Han-Wen Liu, ${ }^{3}$ Yao-Jie Lei, ${ }^{3}$ Lingfei Zhao, ${ }^{3}$ Wang zhang, ${ }^{1}$ Lei Wang, ${ }^{1 *}$ Hirofumi Yoshikawa, ${ }^{5}$ Daiju Matsumura, ${ }^{6}$ Yun-Xiao Wang, ${ }^{3 *}$ Qiao Sun, ${ }^{7}$ Jia-Zhao Wang, ${ }^{3}$ Hua-Kun Liu, ${ }^{3}$ Shu-Lei Chou, ${ }^{3 *}$ Shi-Xue Dou ${ }^{3}$

${ }^{1}$ College of Materials Science and Engineering, Shenzhen University, Shenzhen 518060, China.

${ }^{2}$ College of Physics and Optoelectronic Engineering, Shenzhen University, Shenzhen 518060, China

${ }^{3}$ Institute for Superconducting \& Electronic Materials, University of Wollongong, Innovation Campus, Wollongong, NSW 2500, Australia.

${ }^{4}$ School of Material and Chemical Engineering, Zhengzhou University of Light Industry, Zhengzhou 450002, China.

${ }^{5}$ State Key Laboratory of Radiation Medicine and Protection, Collaborative Innovation Centre of Radiation Medicine of Jiangsu Higher Education Institutions, School for Radiological and Interdisciplinary Sciences, Soochow University, Suzhou 215123, China.

${ }^{6}$ School of Science and Technology, Kwansei Gakuin University, 2-1 Gakuen, Sanda, Hyogo 6691337, Japan.

${ }^{7}$ Quantum Beam Science Center, Japan Atomic Energy Agency, Sayo-gun, Hyogo 679-5148, Japan.

${ }^{8}$ Key Laboratory for Ultrafine Materials of Ministry of Education, Shanghai Key Laboratory of Advanced Polymeric Materials, School of Materials Science and Engineering, East China University of Science and Technology, Shanghai 200237, China.

This PDF file includes:

Supplementary Text

Figs. S1-26

Tables 1-3 


\section{Supplementary text}

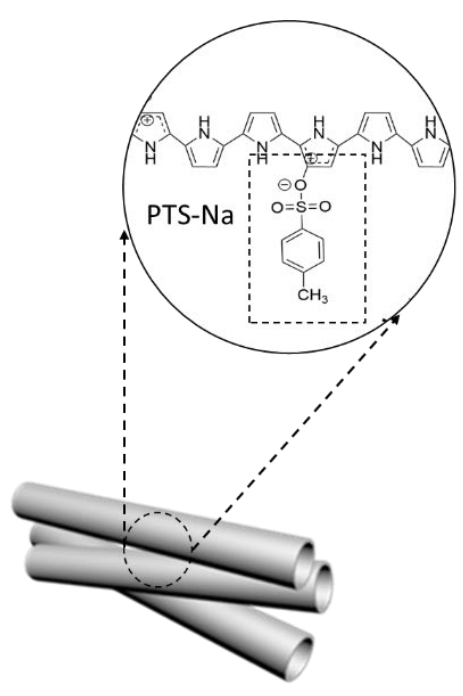

S-PPy

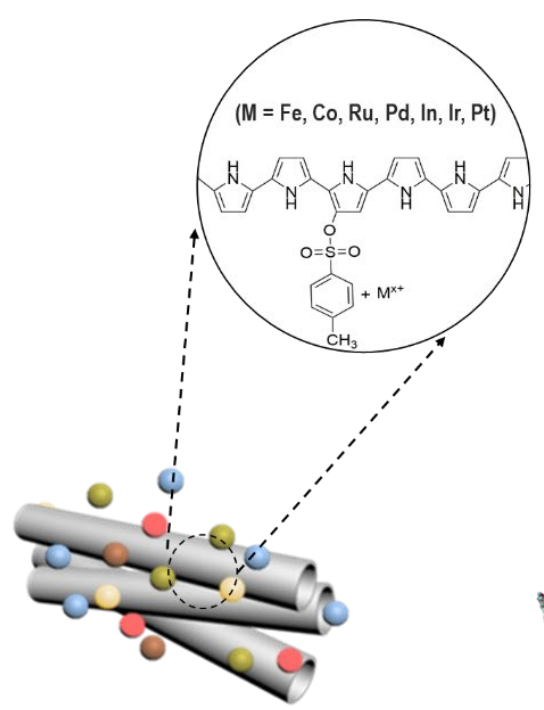

S-PPy-mixture of cations

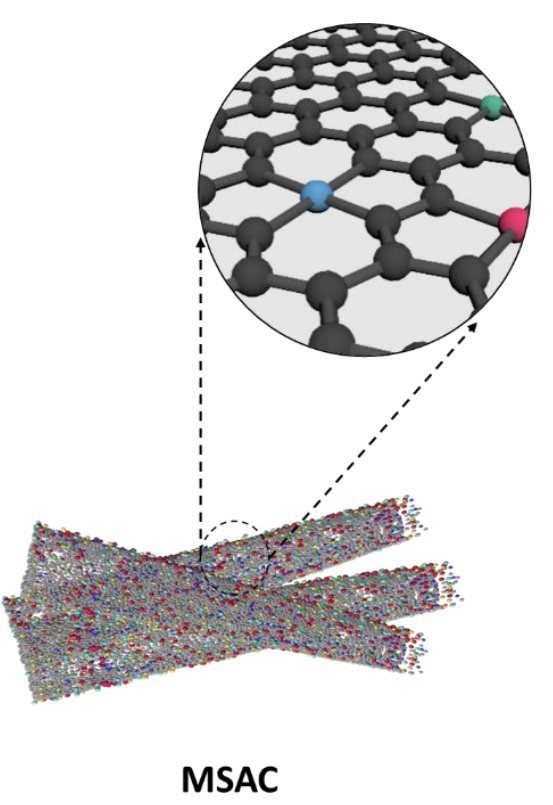

MSAC

Figure S1. The illustration of the synthetic process of MSAC.

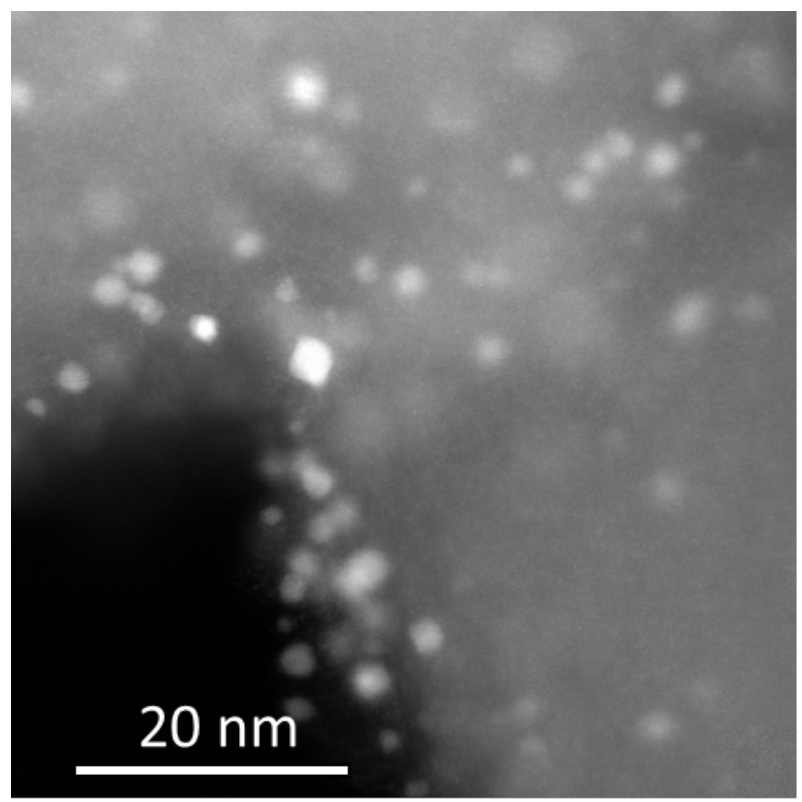

Figure S2. TEM image of Pt particle grown on NC derived from PPy without PTS-Na. 


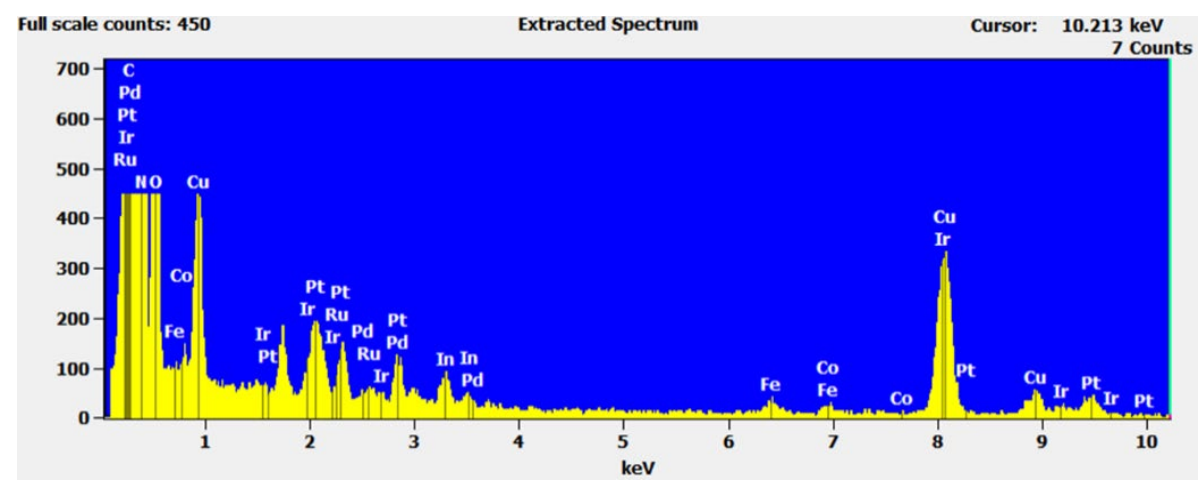

Figure S3. The EDS spectrum of MSAC-7.
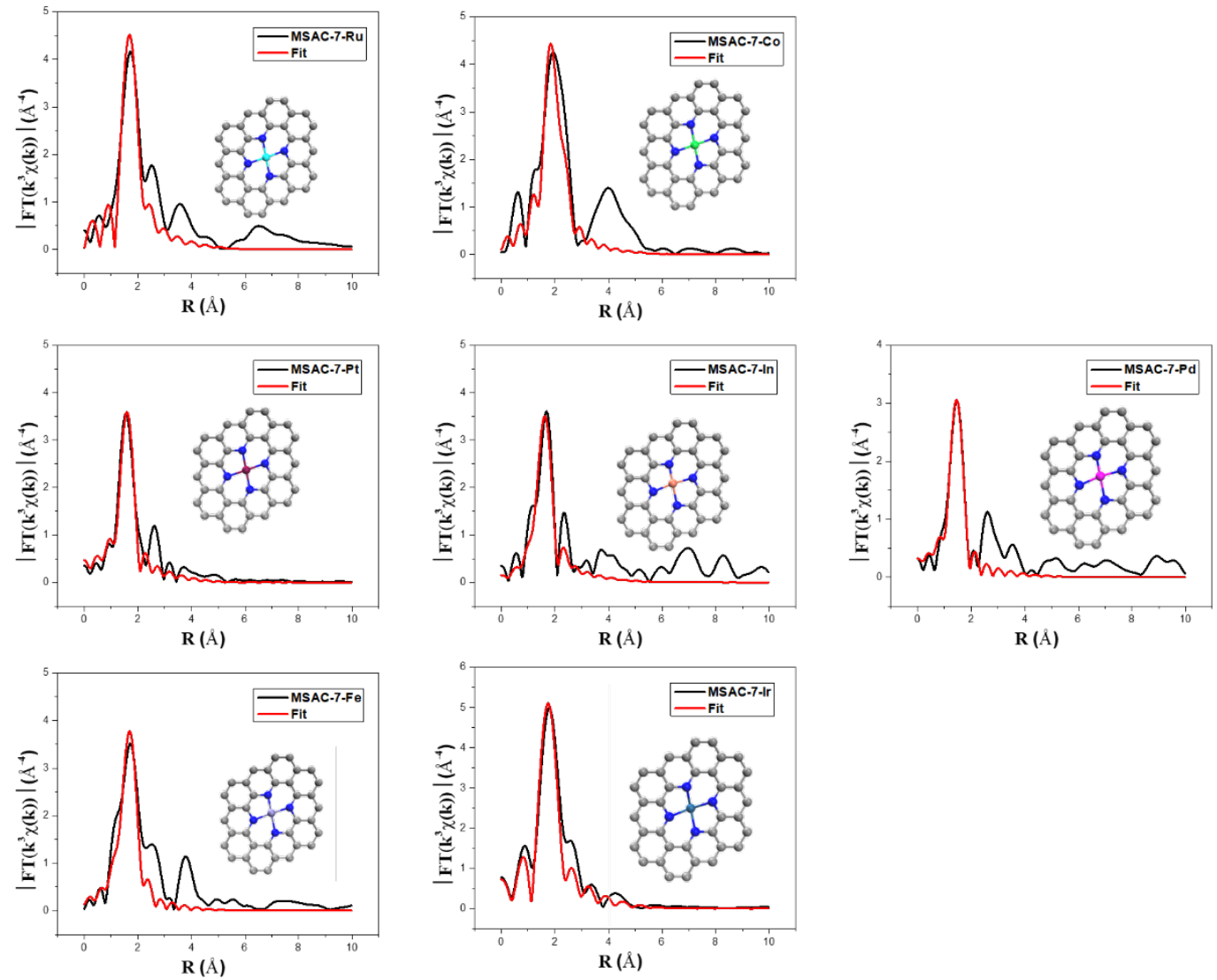

Figure S4. The EXAFS curves of the composed elements in samples MSAC-7 with the corresponding fitting curves as well as the fitted models (inset images). 
Table S1. EXAFS fitting results for MSAC.

\begin{tabular}{|c|c|c|c|c|c|c|}
\hline Sample & Shell & $\mathbf{N}$ & $\mathbf{R}(\AA)$ & $\sigma^{2} \times 10^{2}$ & $\Delta E_{0}(e V)$ & r-factor (\%) \\
\hline \multirow{7}{*}{ MSAC-7 } & Pt-4N & 4 & 2.0202 & 0.8 & 14.7 & 1.88 \\
\hline & $\mathrm{Fe}-4 \mathrm{~N}$ & 4 & 2.3496 & 1.0 & 24 & 2.1 \\
\hline & Ir-4N & 4 & 2.236 & 0.5 & 6.2 & 1.6 \\
\hline & $\mathrm{Pd}-4 \mathrm{~N}$ & 4 & 1.9391 & 0.7 & 5.9 & 0.18 \\
\hline & In-4N & 4 & 2.1675 & 1.2 & 8.4 & 1.9 \\
\hline & $\mathrm{Ru}-4 \mathrm{~N}$ & 4 & 2.1975 & 0.2 & 2.6 & 1.7 \\
\hline & Co-4N & 4 & 2.246 & 0.4 & 33.4 & 16 \\
\hline \multirow{6}{*}{ MSAC-6 } & Pt-4N & 4 & 2.0805 & 1.2 & 17.8 & 1.7 \\
\hline & $\mathrm{Fe}-4 \mathrm{~N}$ & 4 & 2.3496 & 0.9 & 21 & 1.9 \\
\hline & Ir-4N & 4 & 2.206 & 0.5 & 6.2 & 1.6 \\
\hline & Pd-4N & 4 & 1.9391 & 0.7 & 5.9 & 0.18 \\
\hline & Co-4N & 4 & 2.1855 & 1.8 & 14.4 & 1.9 \\
\hline & $\mathrm{Ru}-4 \mathrm{~N}$ & 4 & 2.1655 & 0.8 & 6.6 & 1.7 \\
\hline \multirow{5}{*}{ MSAC-4 } & Pt-4N & 1 & 2.0009 & 0.8 & 13.3 & 0.2 \\
\hline & $\mathrm{Ru}-4 \mathrm{~N}$ & 4 & 1.9652 & 0.8 & 8.3 & 1.1 \\
\hline & Ir-4N & 1 & 1.8309 & 0.6 & 18.6 & 1.1 \\
\hline & $\mathrm{Fe}-4 \mathrm{~N}$ & 1 & 2.0290 & 0.3 & 9.6 & 0.5 \\
\hline & $\mathrm{Fe}-1 \mathrm{C} / 1 \mathrm{~N}$ & 2 & 1.4501 & 0.8 & 30 & 0.7 \\
\hline
\end{tabular}

$N$ : the coordination number of the absorber-backscatter pair; $R$ : the average absorber-backscatter distance; $\sigma^{2}$ : the Debye-Waller factor; $\Delta E_{0}$, the inner potential correction.

Table S2. Content of elements for MSAC samples.

\begin{tabular}{lllllllll}
\hline & Pt/wt. \% & Ir/wt. \% & Pd/wt. \% & Ru/wt. \% & Fe/wt. \% & Co/wt. \% & In/wt. \% & Total/wt. \% \\
\hline MSAC-7 & 0.2 & 0.29 & 0.22 & 0.15 & 0.22 & 0.12 & 0.18 & 1.38 \\
\hline MSAC-6 & 0.17 & 0.27 & 0.18 & 0.2 & 0.13 & 0.14 & 1.09 \\
\hline MSAC-5 & 0.22 & 0.47 & & 0.35 & 0.18 & 0.15 & 1.37 \\
\hline MSAC-4 & 0.21 & 0.31 & & 0.19 & 0.35 & & 1.06 \\
\hline MSAC-3 & 0.22 & 0.56 & & & 0.19 & & 0.97 \\
\hline MSAC-2 & 0.86 & & & 0.19 & & 1.05 \\
\hline Pt $@$ NC & 0.8 & & & & & & 0.8 \\
\hline
\end{tabular}



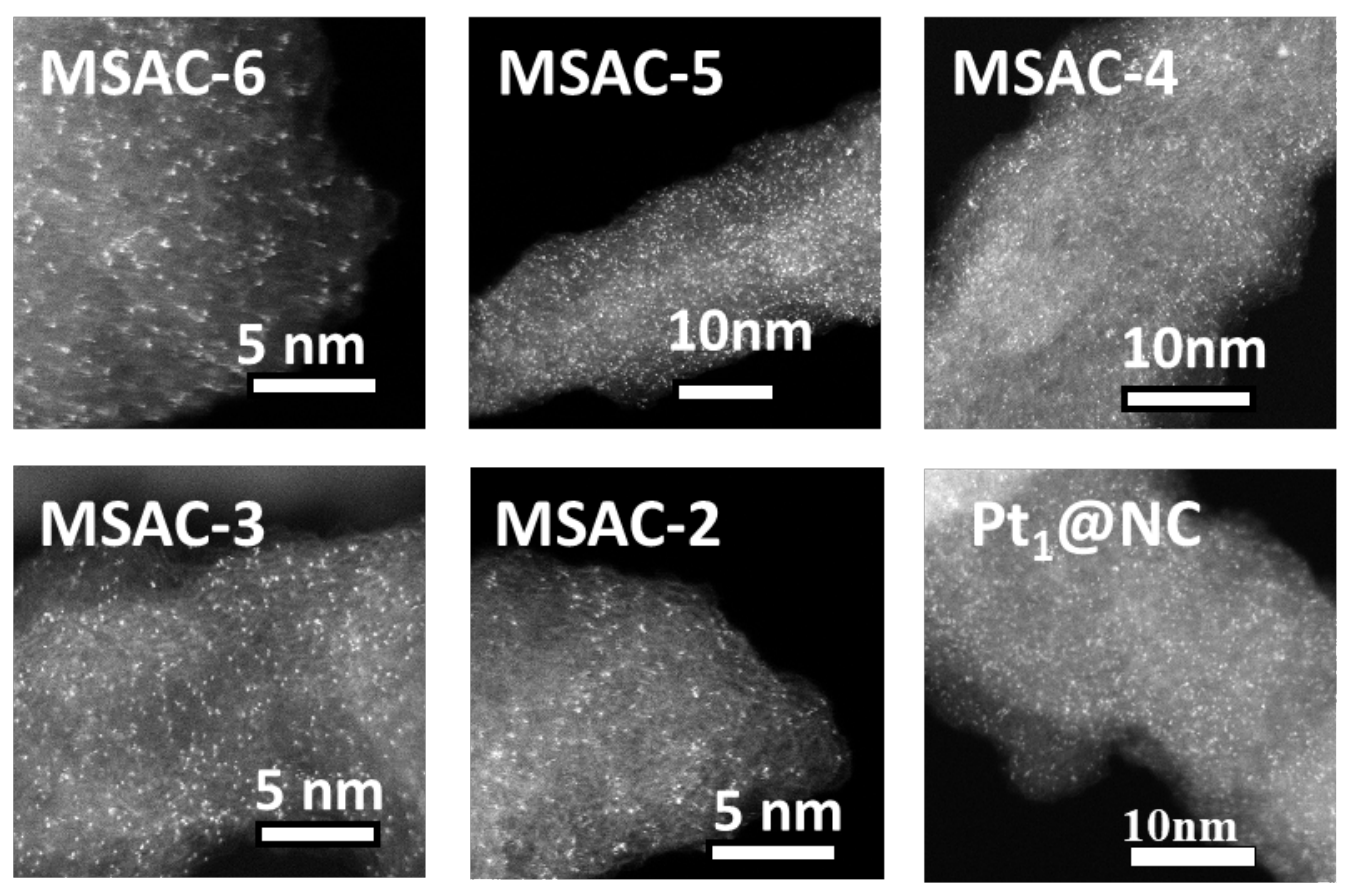

Figure S5. HAADF images of samples MSAC-6, MSAC-5, MSAC-4, MSAC-3, MSAC-2, and $\mathrm{Pt}_{1} @ \mathrm{NC}$. 

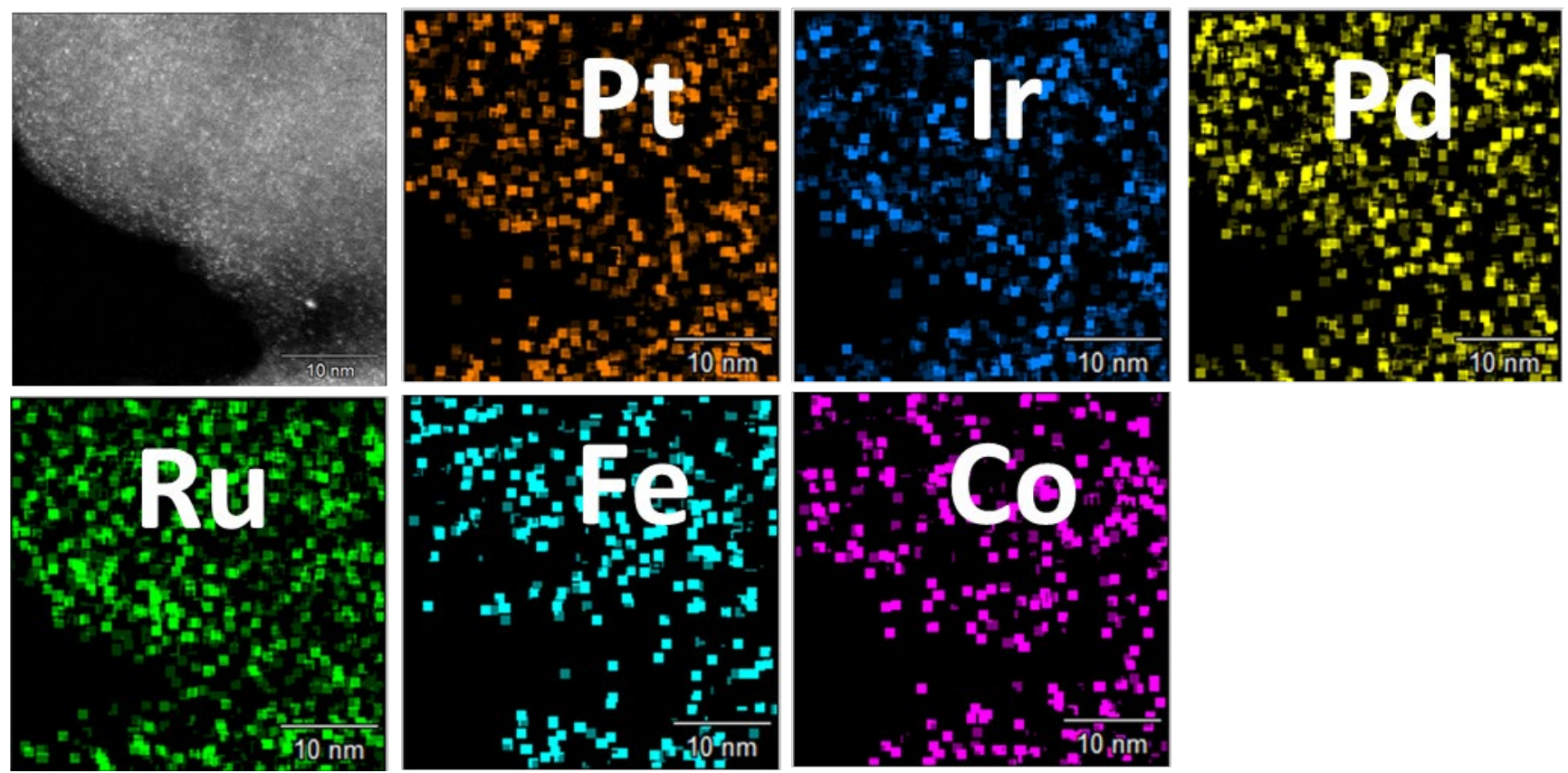

Figure S6. Elemental mapping of MSAC-6.
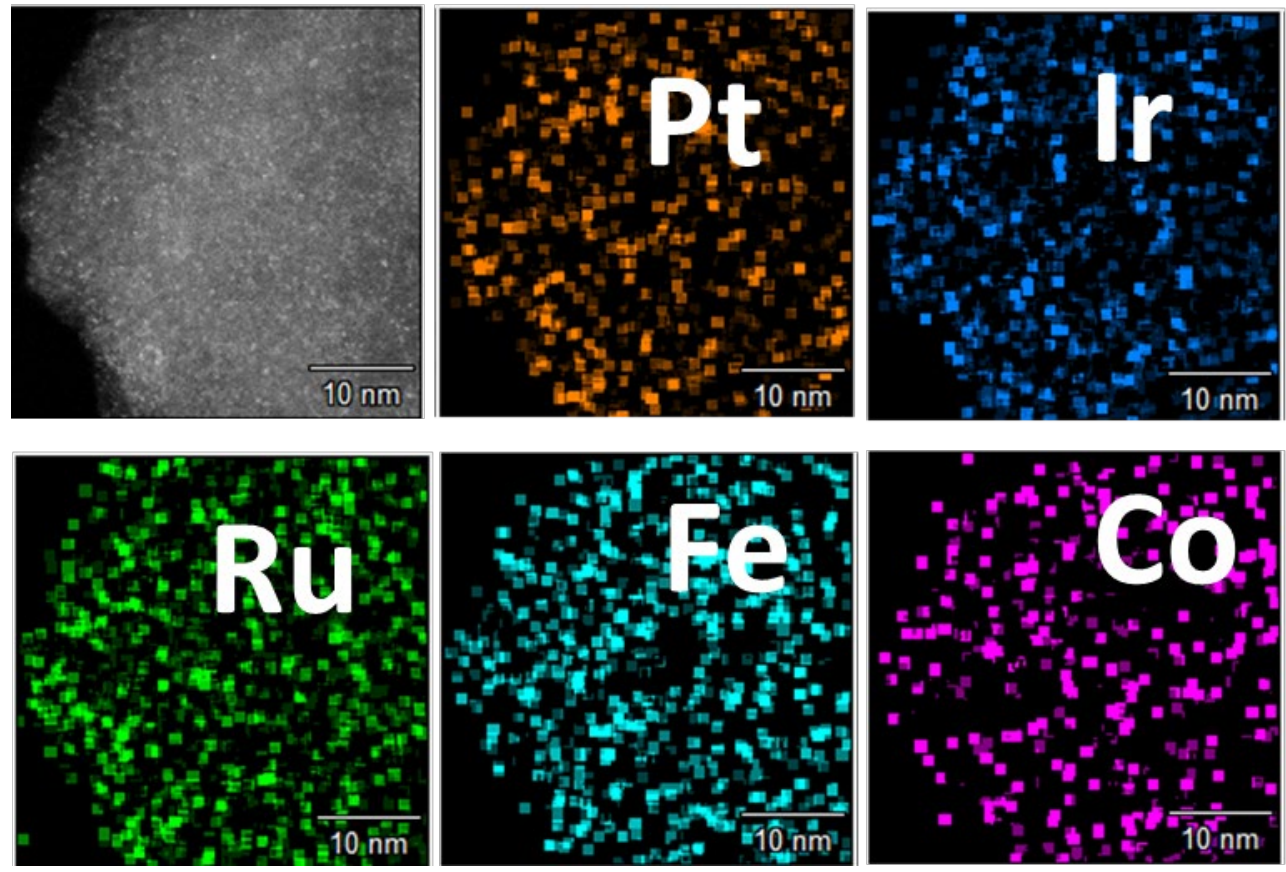

Figure S7. Elemental mapping of MSAC-5. 

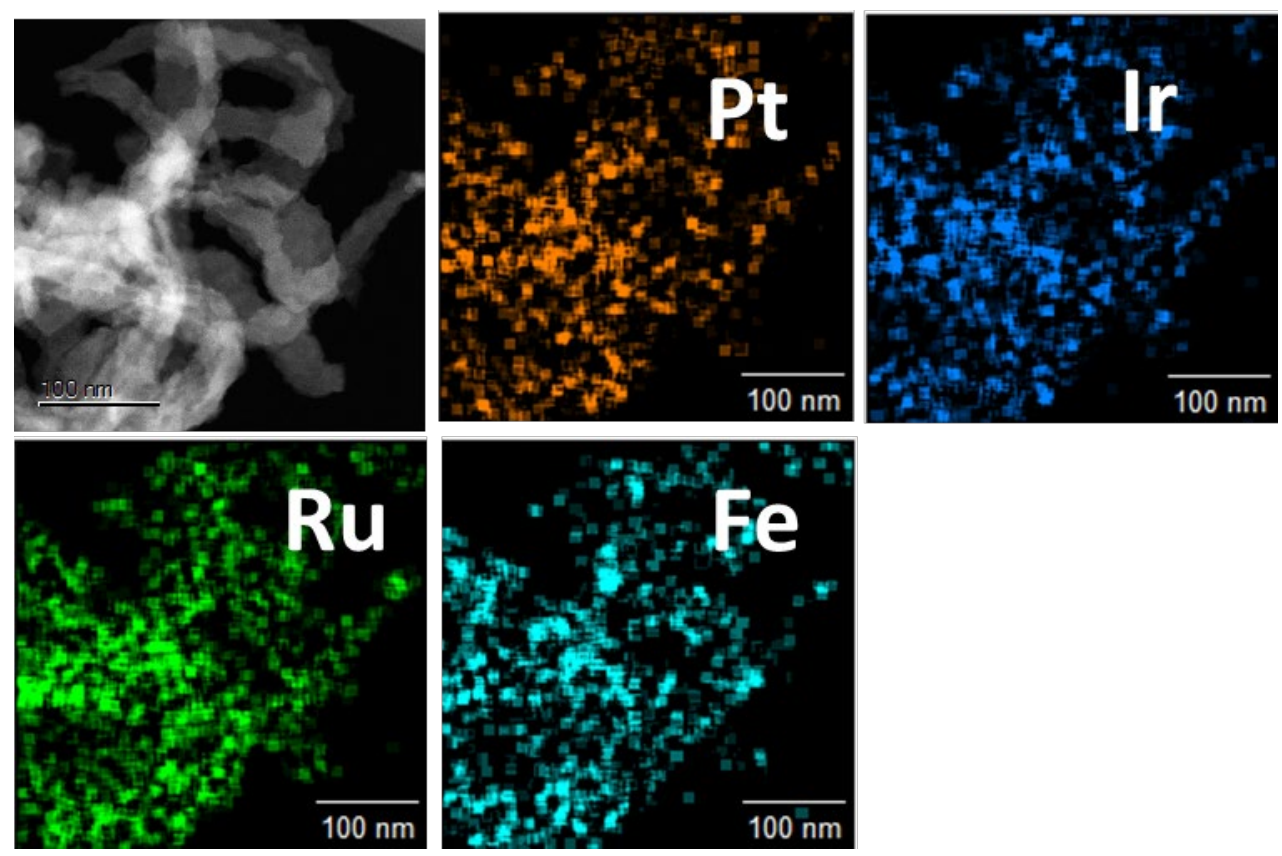

Figure S8. Elemental mapping of MSAC-4.
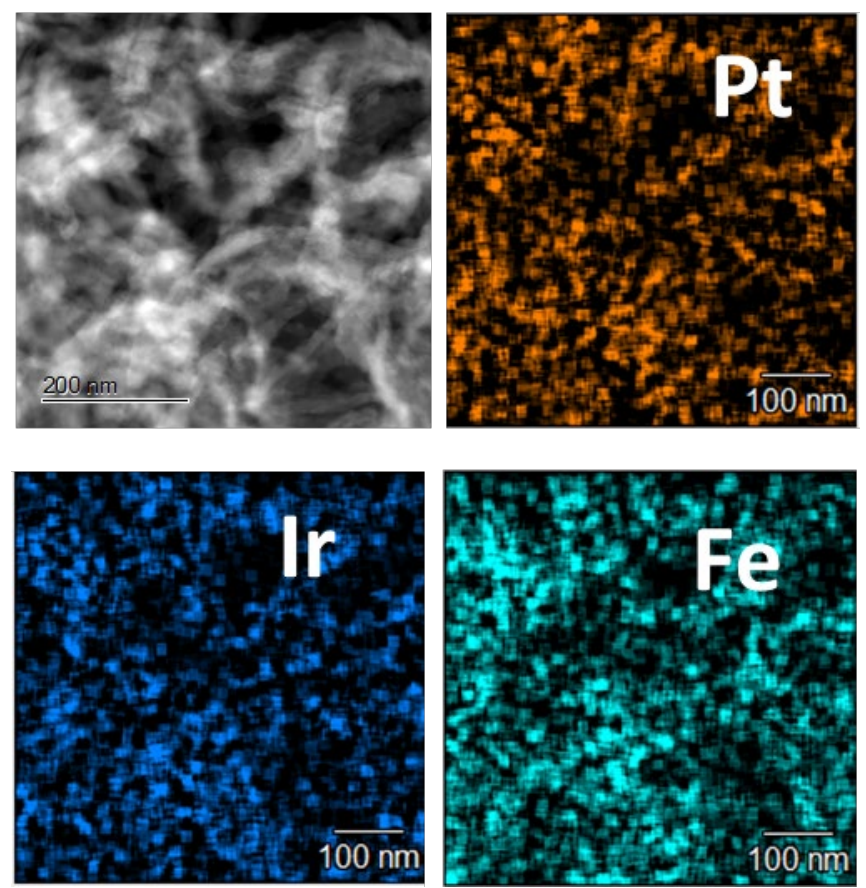

Figure S9. Elemental mapping of MSAC-3. 

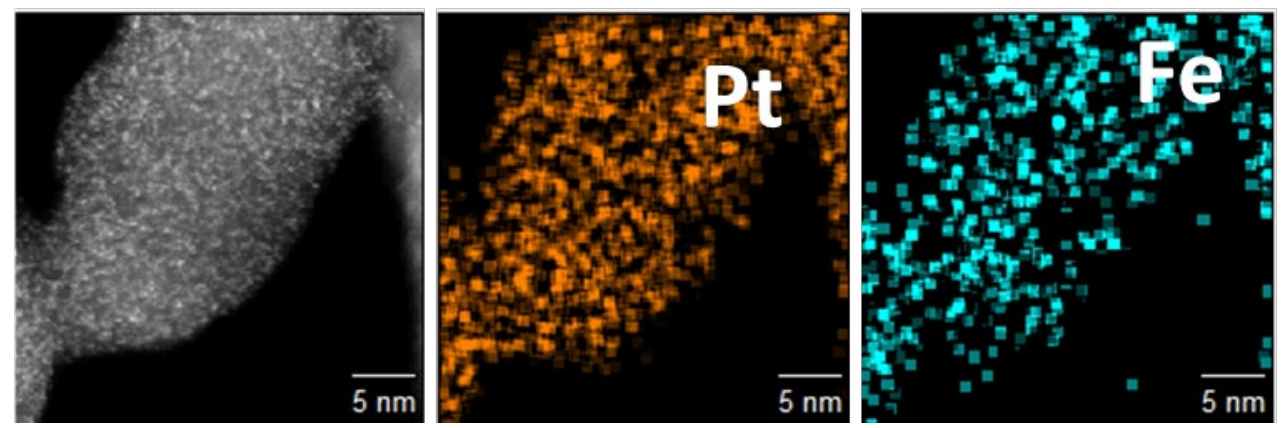

Figure S10. Elemental mapping of MSAC-2.
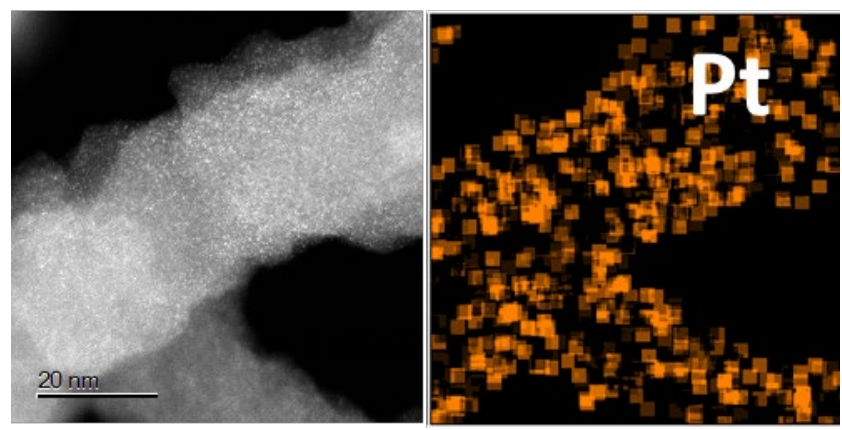

Figure S11. Elemental mapping of MSAC-2.
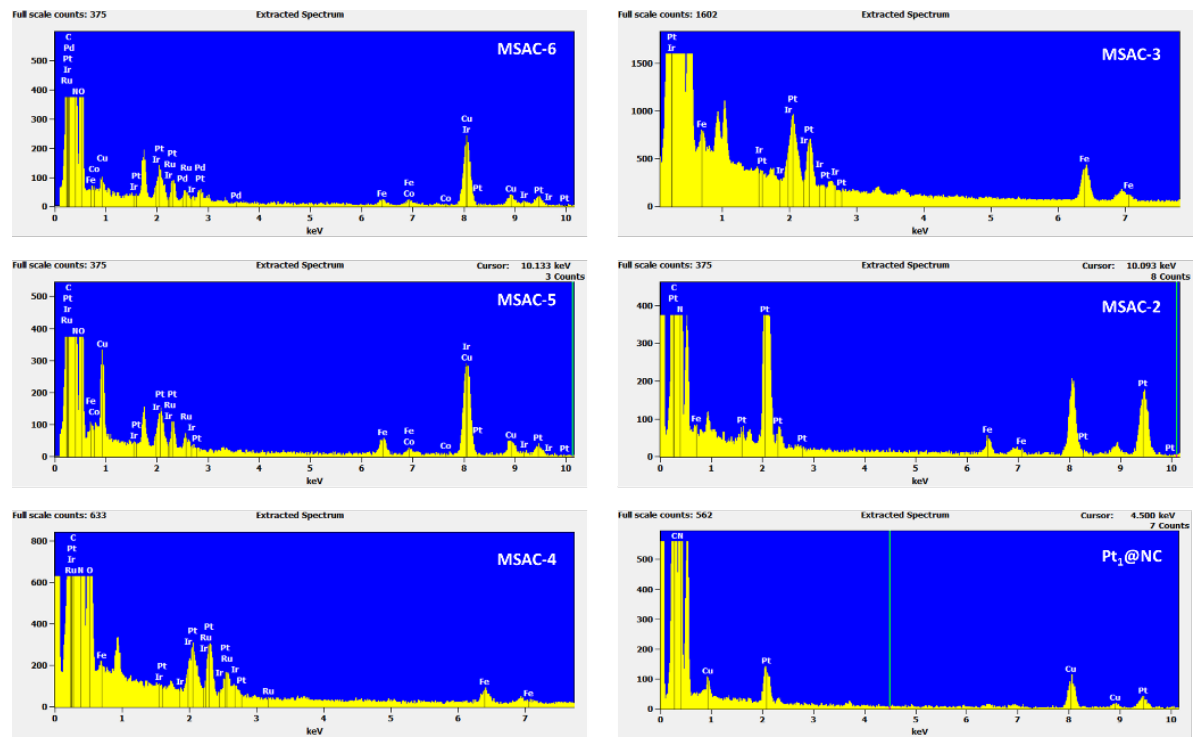

Figure S12. The EDS spectra of MSAC-6, MSAC-5, MSAC-4, MSAC-3, MSAC-2, and Pt $@$ @NC. 

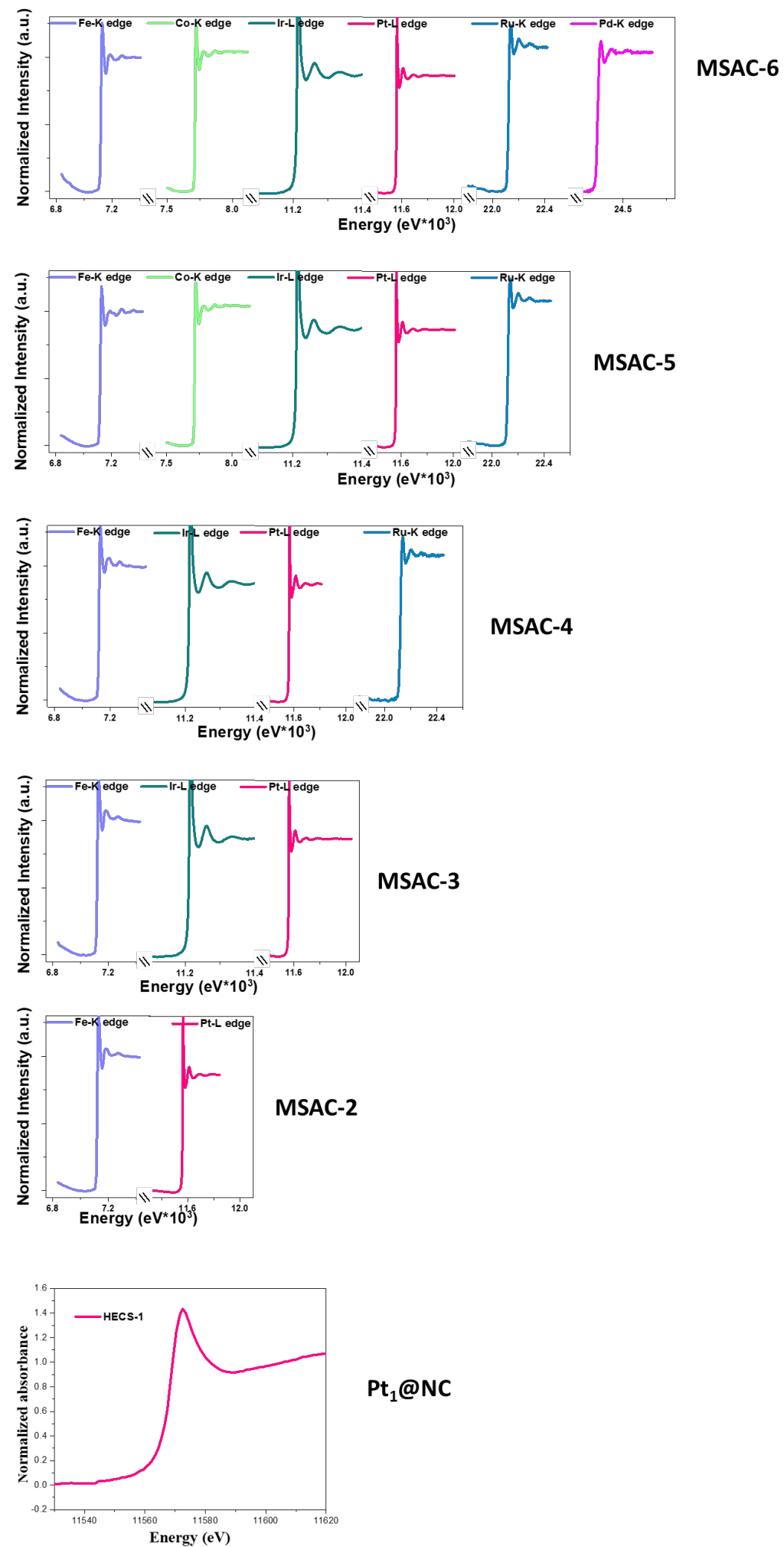

Figure 13. The XAS spectra of MSAC-6, MSAC-5, MSAC-4, MSAC-3, MSAC-2, and Pt $@$ NC. 


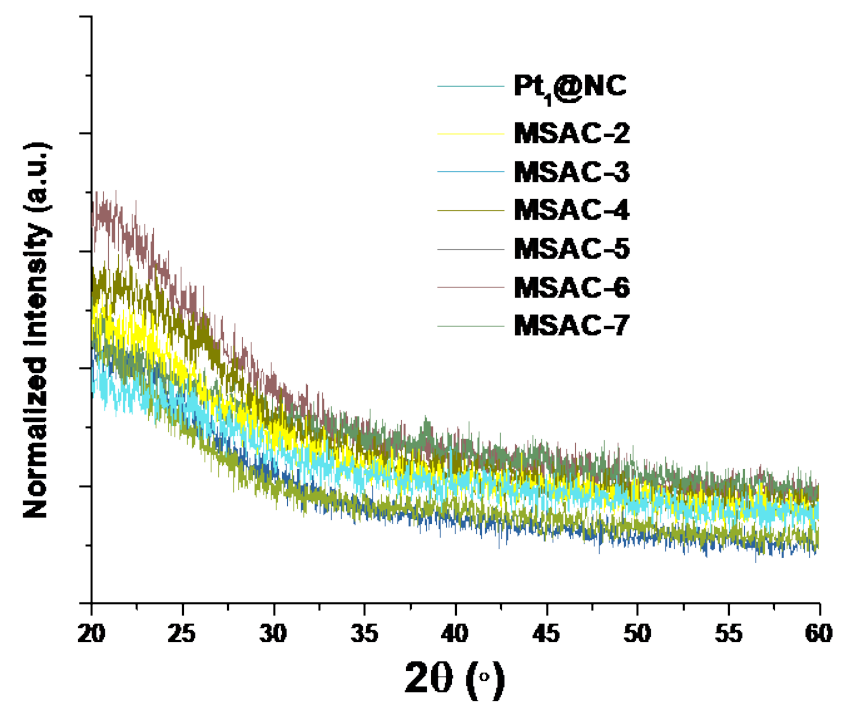

Figure S14. XRD patterns of Pt 1 @NC, MSAC-7, MSAC-6, MSAC-5, MSAC-4, MSAC-3, and MSAC-2.
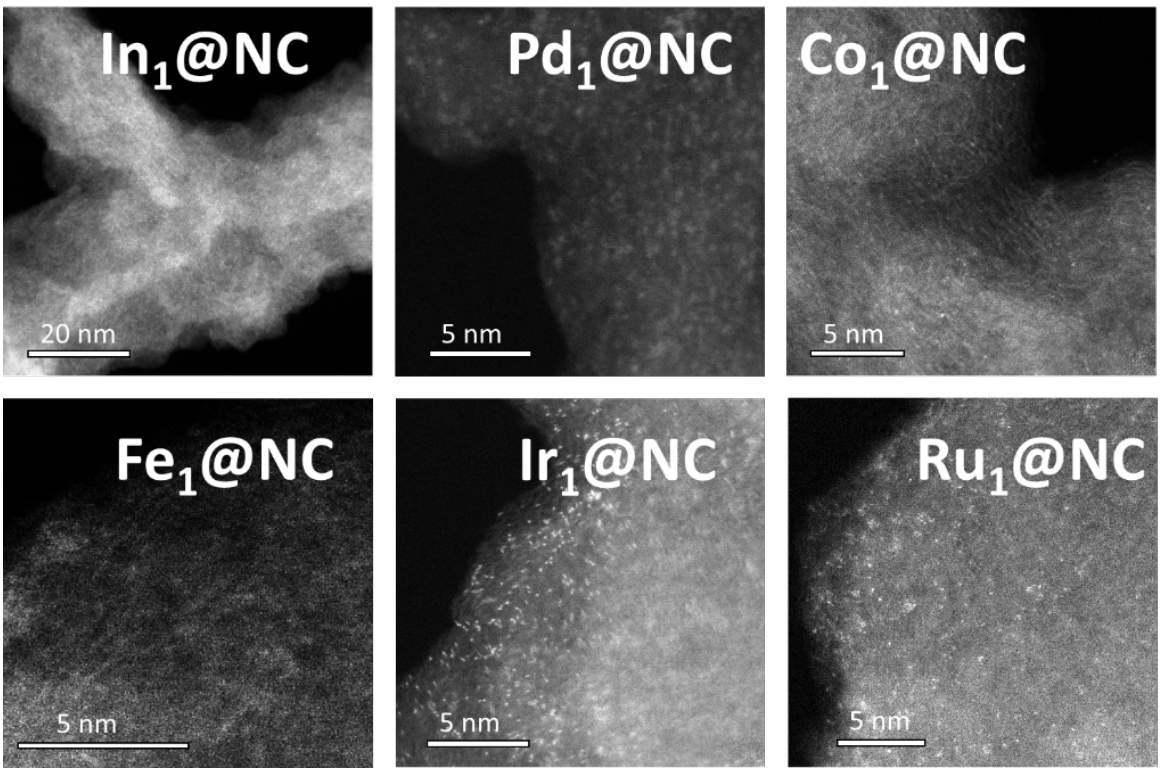

Figure S15. HAADF images of samples Ir $\mathrm{r}_{1} @ \mathrm{NC}, \mathrm{Ru} \mathrm{u}_{1} @ \mathrm{NC}, \mathrm{Co}{ }_{1} @ \mathrm{NC}, \mathrm{Fe}_{1} @ \mathrm{NC}, \mathrm{In}_{1} @ \mathrm{NC}$, and $\mathrm{Pd}_{1} @ \mathrm{NC}$. 

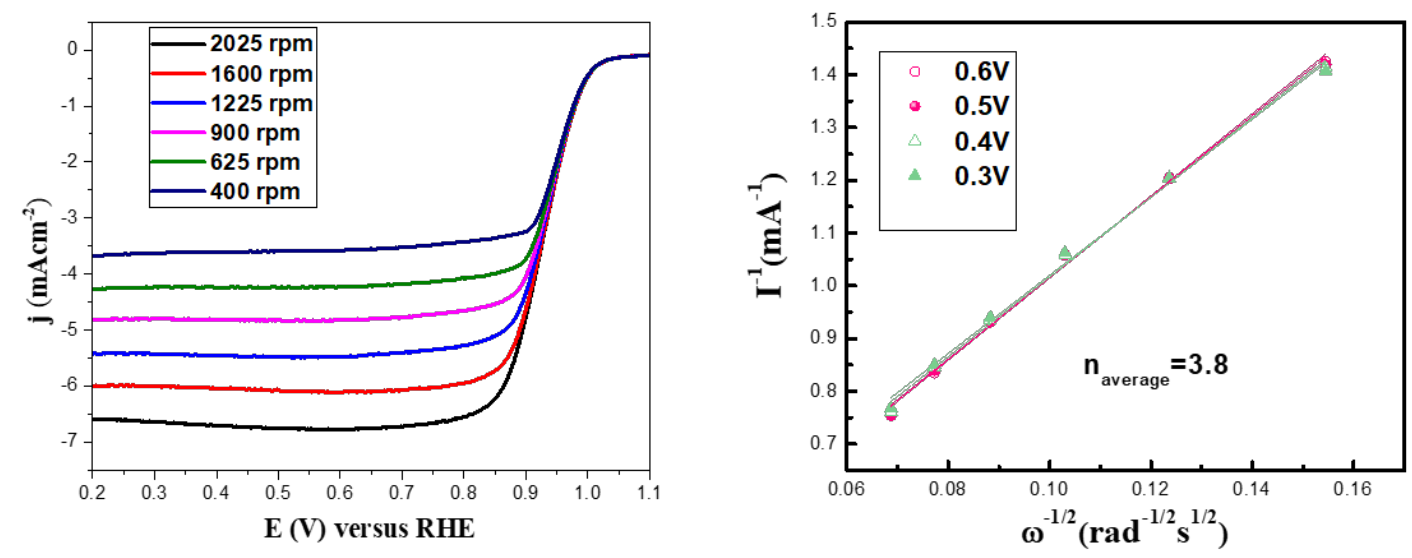

Figure S16. Koutecky-Levich plots from the ORR data for MSAC-6 at different potentials, (b) the rotation-rate-dependent current-potential curves. 
Table 3. Comparison of the performance between MSAC-7 and state-of-the-art PGM-based catalysts from literature.

\begin{tabular}{|c|c|c|}
\hline Catalyst & Mass activity@0.9 V (A mg $\left.{ }^{-1}{ }_{\text {PMG }}\right)$ & Reference \\
\hline MSAC-6 & 18.1 & This work \\
\hline PdMo bimetallene/C & 16.37 & $\begin{array}{l}\text { Nature } 574,81-85 \\
\text { (2019). }\end{array}$ \\
\hline PtPb nanoplates $/ \mathrm{C}$ & 0.47 & $\begin{array}{l}\text { Nature } 574,81-85 \\
\text { (2019). }\end{array}$ \\
\hline PtNi h-nanowires/C & 0.32 & $\begin{array}{c}\text { Nature } 574,81-85 \\
\text { (2019). }\end{array}$ \\
\hline PtNi u-nanowires/C & 0.14 & $\begin{array}{l}\text { Nature 574, } 81-85 \\
\text { (2019). }\end{array}$ \\
\hline Pd bimetallene/C & 0.65 & $\begin{array}{l}\text { Nature } 574,81-85 \\
\text { (2019). }\end{array}$ \\
\hline $\mathrm{Pt} / \mathrm{MnO}_{\mathrm{x}}$ & 4 & $\begin{array}{c}\text { Catalyst today } \\
\text { 332, 101-108 } \\
\text { (2019). }\end{array}$ \\
\hline $\mathbf{P t}_{1}-\mathbf{N} / \mathbf{B P}$ & 0.67 & $\begin{array}{c}\text { Nat. Comm. 8, } \\
15938 \text { (2017) }\end{array}$ \\
\hline H-Pt/CaMnO3 & $0.38 @ 0.85 \mathrm{~V}$ & $\begin{array}{l}\text { Adv. Mater 26, } \\
2047 \text { (2014). }\end{array}$ \\
\hline Pd-P & $1.34 @ 0.85 \mathrm{~V}$ & $\begin{array}{l}\text { J. Am. Chem. Soc } \\
137,5217 \text { (2015). }\end{array}$ \\
\hline $\mathrm{Au} / \mathrm{Cu}_{40} \mathrm{Pd}_{60}$ & 0.43 & $\begin{array}{l}\text { J. Am. Chem. Soc } \\
136,15026 \text { (2014). }\end{array}$ \\
\hline AuCoPd & 0.13 & $\begin{array}{c}\text { Nat. Comm. 5, } \\
5185 \text { (2014) }\end{array}$ \\
\hline $\mathrm{CuCoPd} / \mathrm{C}$ & 0.13 & $\begin{array}{c}\text { Angew. Chem. Int. } \\
\text { Ed 55, } 9030 \\
(\mathbf{2 0 1 6}) .\end{array}$ \\
\hline
\end{tabular}




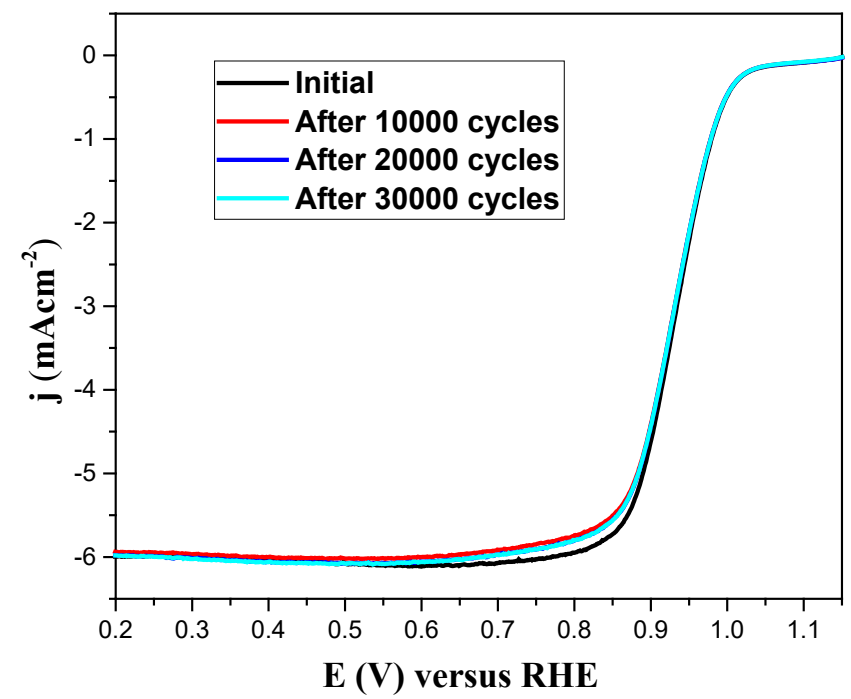

Figure 17. The ORR polarization curves for MSAC-6 before and after 30000 potential cycles.
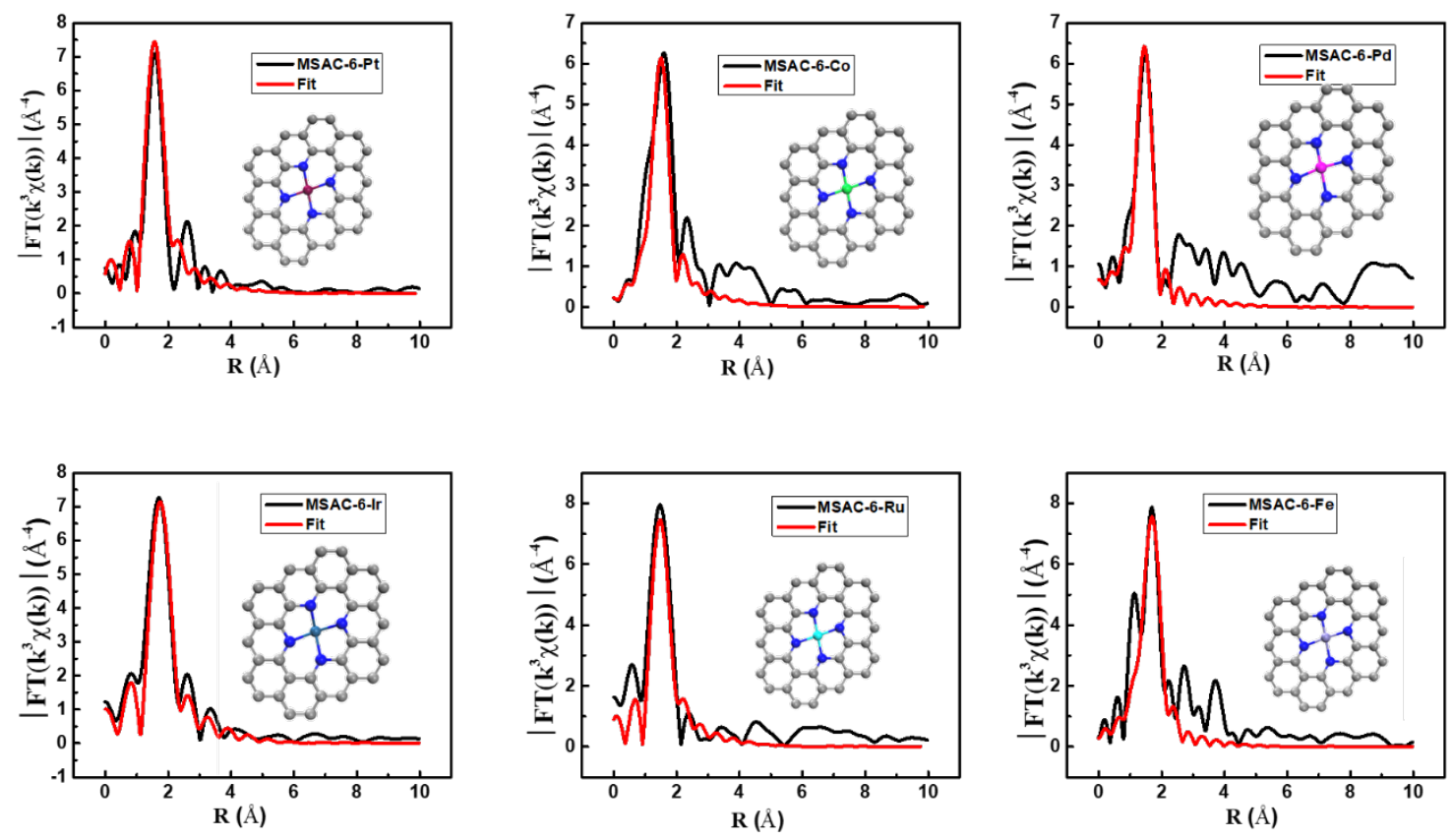

Figure S18. The EXAFS curves of the composed elements in samples MSAC-7 with the corresponding fitting curves as well as the fitted models (inset images). 

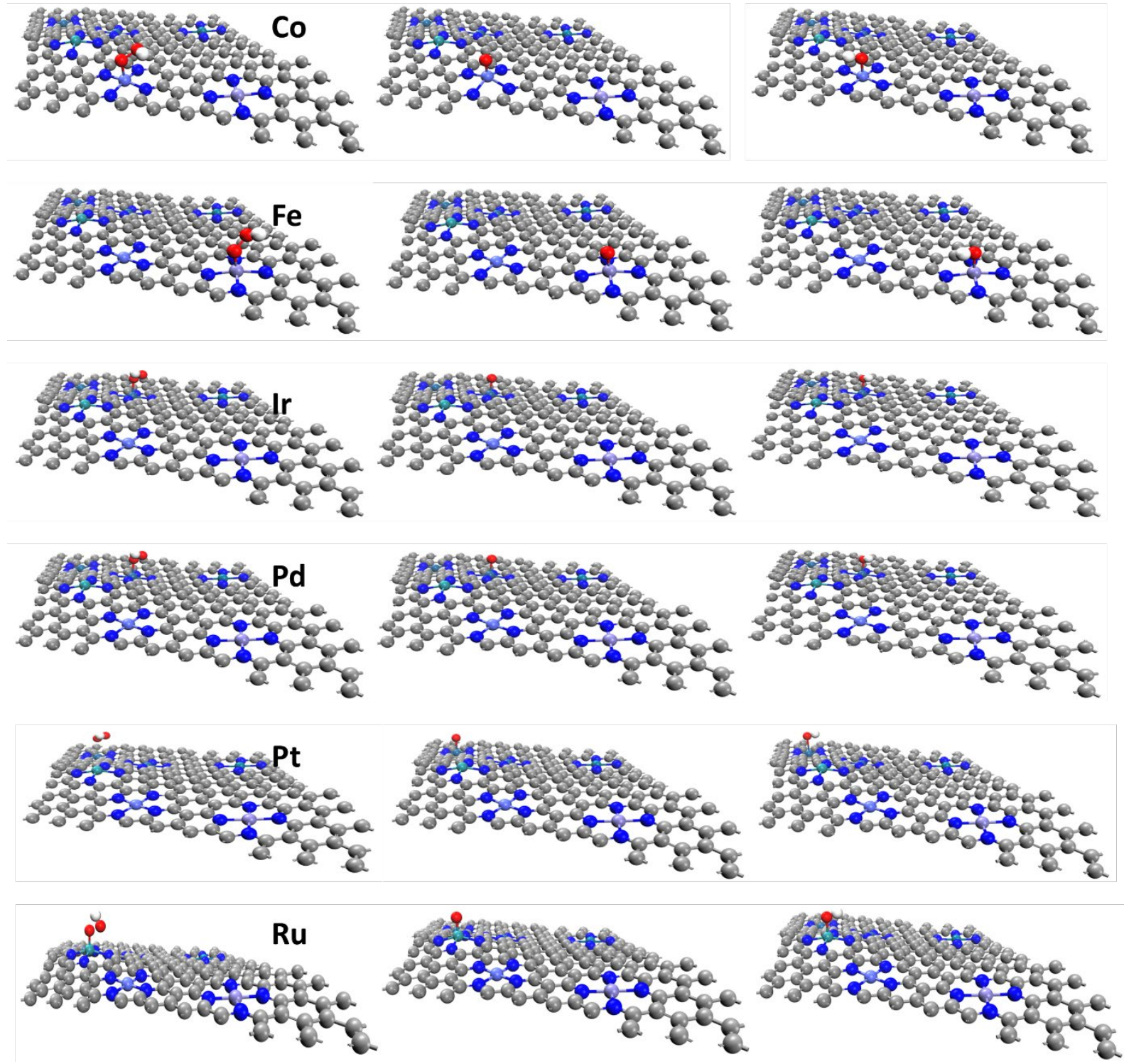

Figure 19. The optimized structures of $\mathrm{OOH}^{*}, \mathrm{O}^{*}, \mathrm{OH}^{*}$ adsorbing on MSAC-6. 


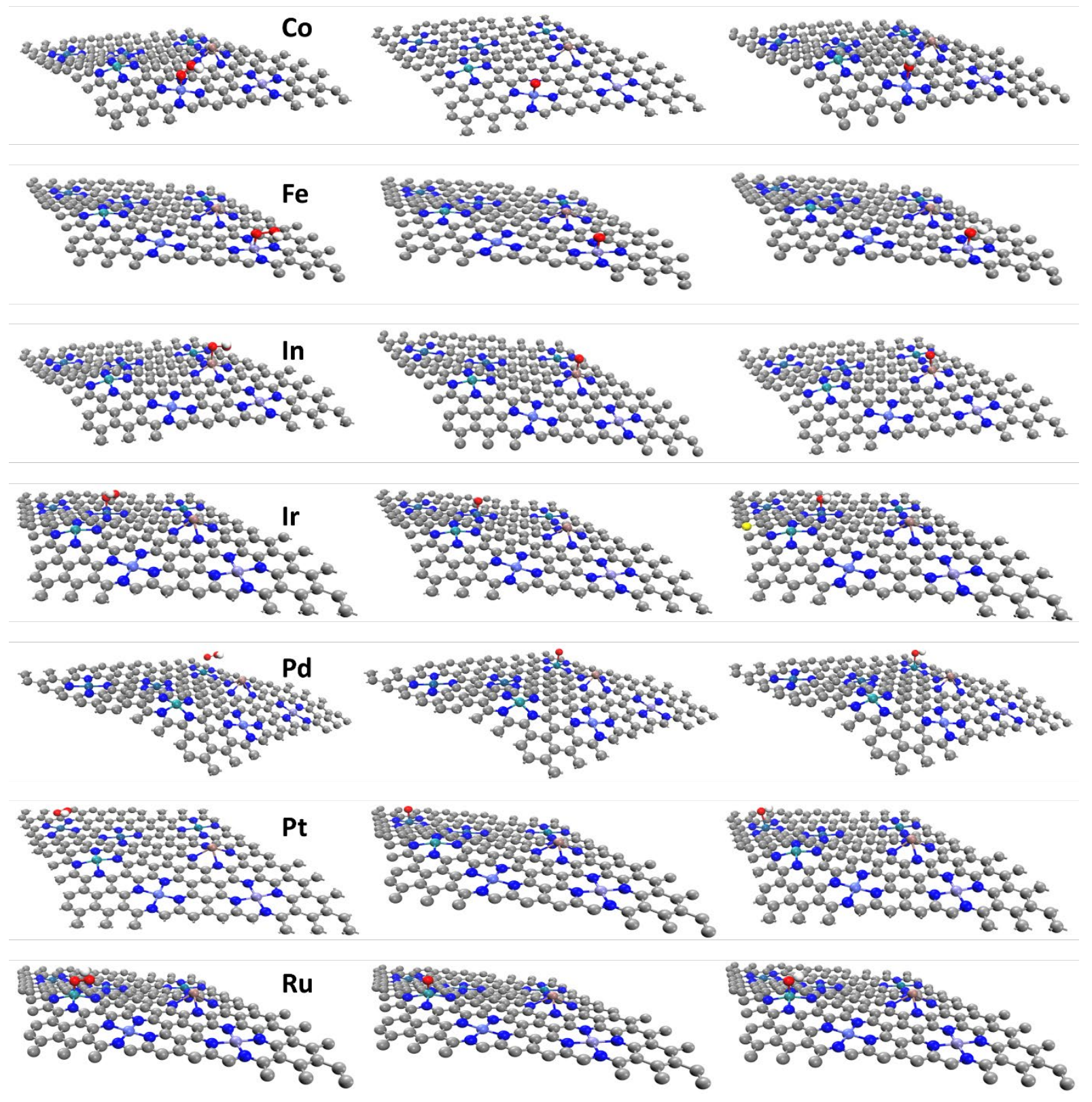

Figure 20. The optimized structures of $\mathrm{OOH}^{*}, \mathrm{O}^{*}, \mathrm{OH}^{*}$ adsorbing on MSAC-6. 


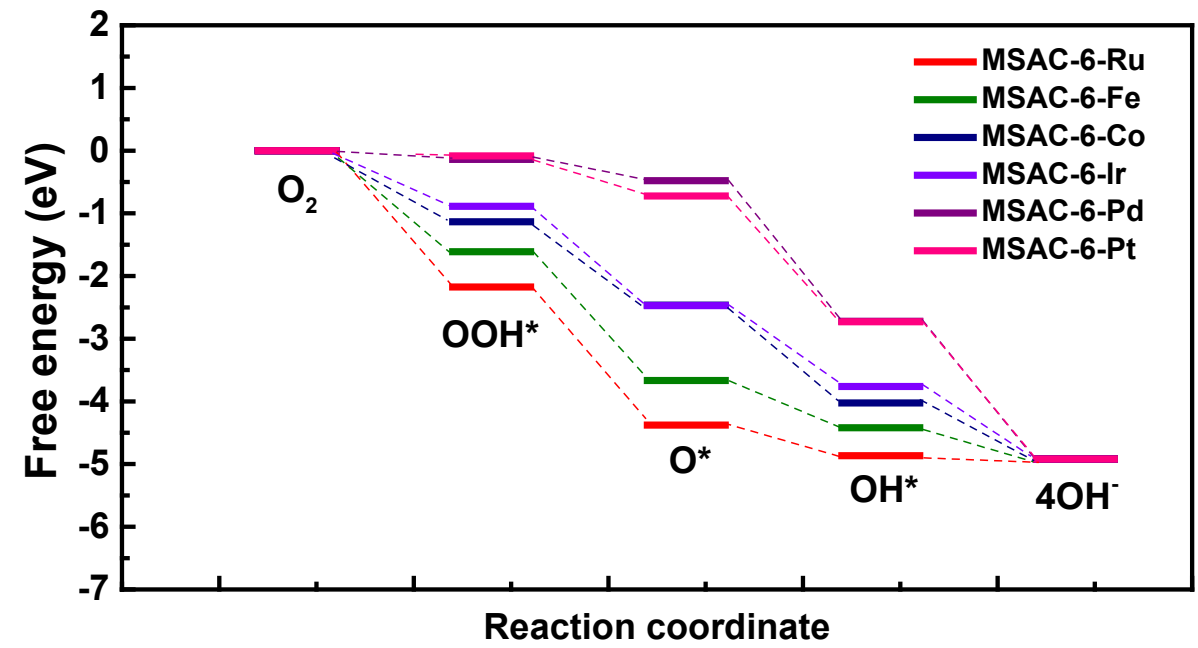

Figure 21. The Gibbs free energy profiles of $\mathrm{OOH}^{*}, \mathrm{O}^{*}, \mathrm{OH}^{*}$ on each single-atom unit of MSAC6.

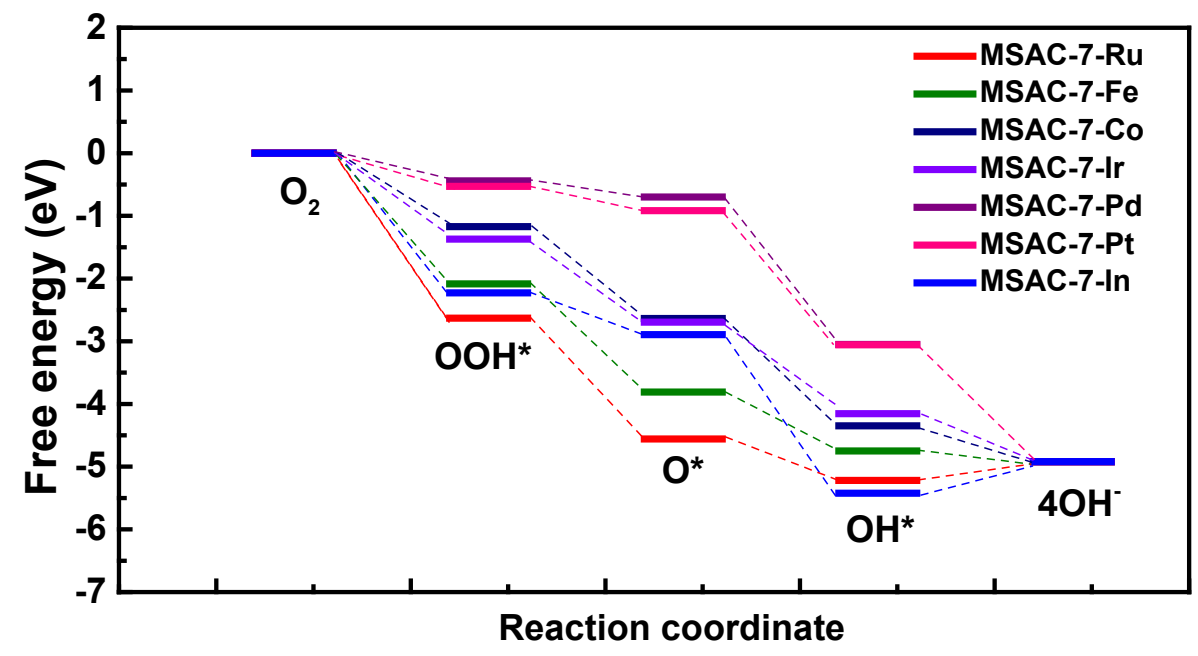

Figure 22. The Gibbs free energy profiles of $\mathrm{OOH}^{*}, \mathrm{O}^{*}, \mathrm{OH}^{*}$ on each single-atom unit of MSAC7. 

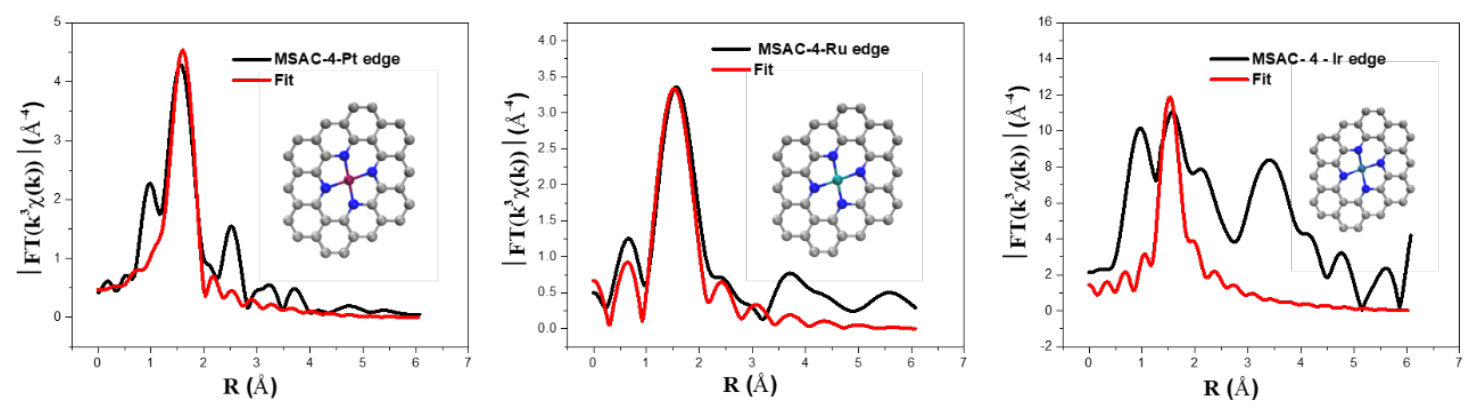

Figure S23. The EXAFS curves of the composed elements: $\mathrm{Pt} / \mathrm{Ir} / \mathrm{Ru}$ in samples MSAC-4 and their corresponding fitting curves, the inset images are the fitted models.
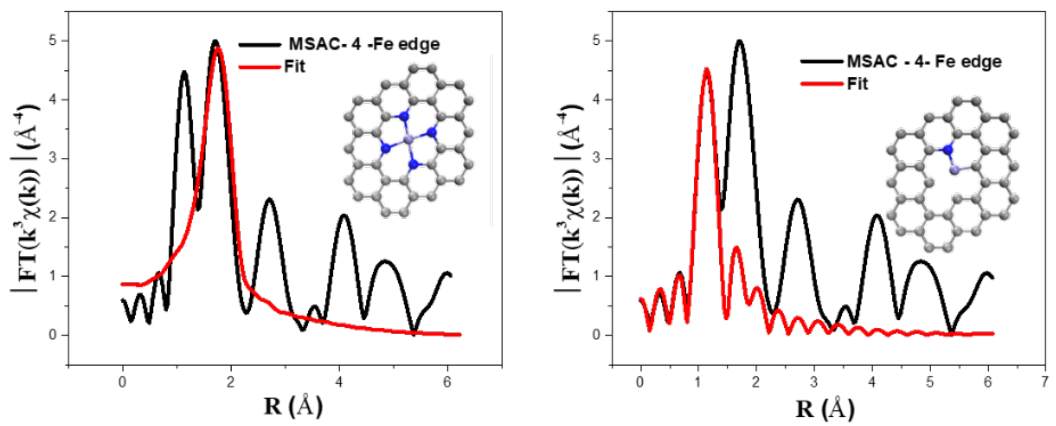

Figure S24. The EXAFS curves of the composed elements: Fe in samples MSAC-4 and their corresponding fitting curves, the inset images are the fitted models. 


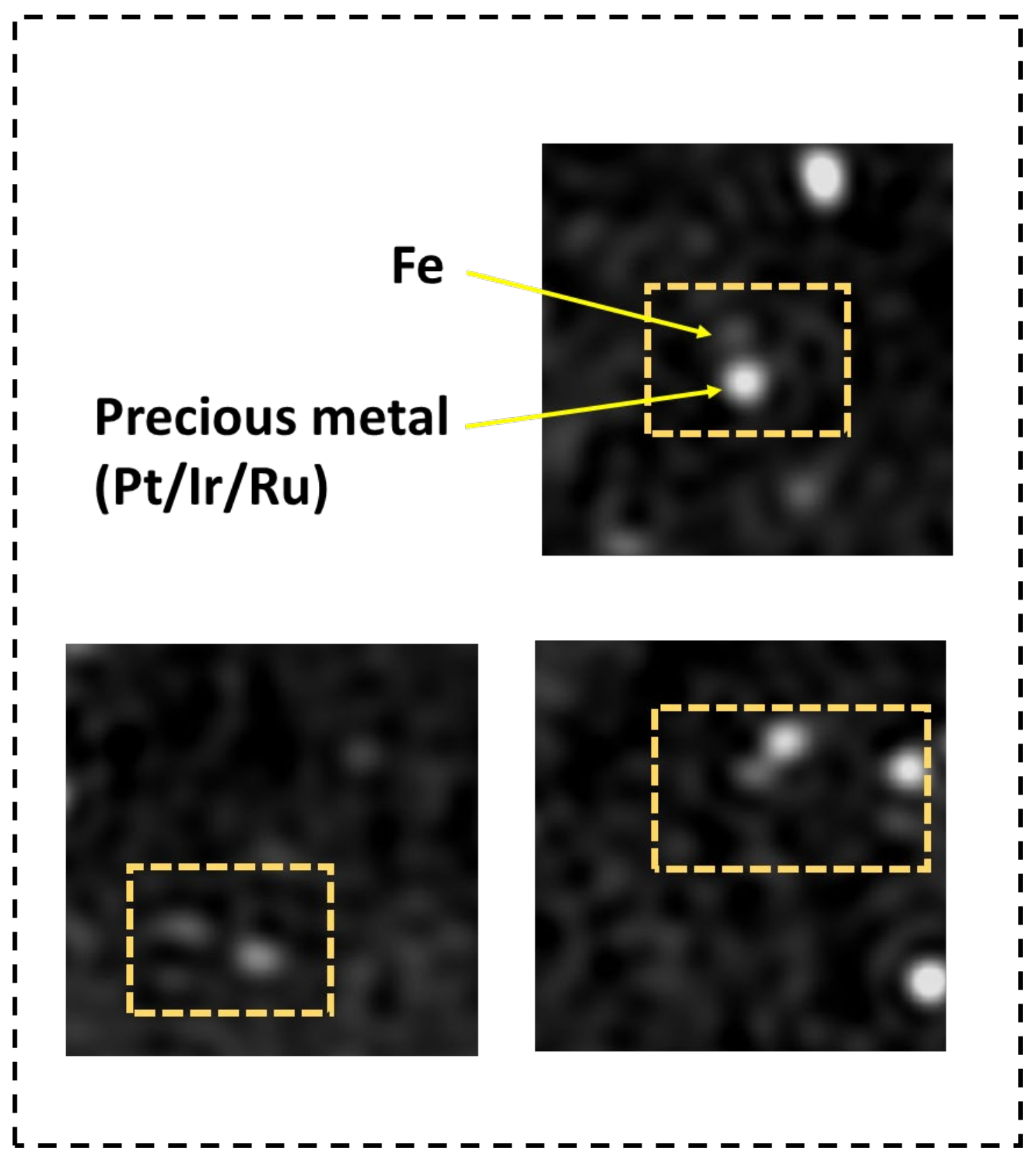

Figure S25. The typical high-resolution fast Fourier transform inversed (FFTI)-HAADF images of MSAC-4. 

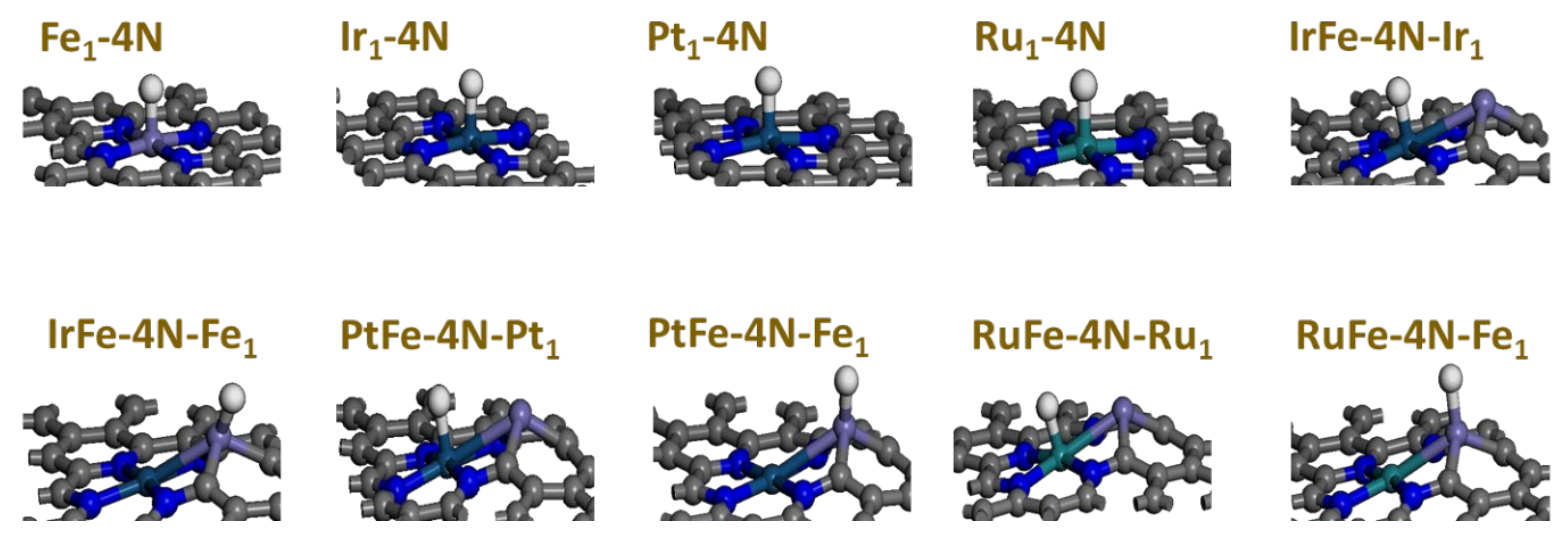

Figure S26. The optimized structures of $\mathrm{H}$ adsorbing on $\mathrm{Fe}_{1}-4 \mathrm{~N}, \mathrm{Pt}_{1}-4 \mathrm{~N}, \mathrm{Ir}_{1}-4 \mathrm{~N}, \mathrm{Ru}_{1}-4 \mathrm{~N}, \mathrm{IrFe}-$ 4N-Ir 1 (Ir site), IrFe-4N-Fe 1 (Fe site), PtFe-4N-Pt 1 (Pt site), PtFe-4N-Fe 1 (Fe site), RuFe-4N-Ru 1 (Ru site), RuFe-4N-Fe 1 (Fe site). 
